\title{
Antecedents of the propensity to learn management practices and their impacts on firm outcomes in emerging markets: A Bayesian Model Averaging Approach
}

\author{
Abdilahi Ali \\ Salford Business School, University of Salford, UK \\ Syed Imran Ali \\ Huddersfield Business School, University of Huddersfield, UK
}

\begin{abstract}
This article explores the factors that motivate firms to learn new management practices. The hypotheses are empirically tested using a representative sample of 3,676 small, medium and large firms from four South Asian countries and across all main sectors of economic activity. Given that we know little about the antecedents of the propensity to learn management practices in emerging markets, the study employs Bayesian Model Averaging approach to overcome the potential issue of model uncertainty. The results reveal that market competition, resource allocation towards internal and external $\mathrm{R} \& \mathrm{D}$, good quality mobile network coverage and the use of external certified financial auditors have all positive and significant effects on the propensity to learn management practices. The results also suggest that private intellectual property rights protection in the context of inefficient legal systems can deter firms from learning, perhaps in fear of legal ramifications. Finally, the study shows that firms with a higher propensity of learning management practices are more likely to become profitable while exhibiting higher levels of both potential and actual innovation.
\end{abstract}

JEL classification: L2, O32, O33

Keywords: management practices; organisational learning; Bayesian Model Averaging approach; South Asia; firm innovation; firm growth. 


\section{Introduction}

Management practices are considered to be important drivers of firm productivity, growth and survival (Heyman et al., 2019; Nieves, 2016; Bloom et al., 2019). This is because they encompass organisational and administrative capabilities which can enhance the viability and efficiency of firm operations. Management practices include, among other things, performance and people management, e.g. monitoring, target setting, feedback mechanisms, selection and incentive-based policies (Forth and Bryson, 2019). They also include operational and organisational processes, e.g. long-run planning, justin-time processes and quality circles (Bloom and Van Reenen, 2010; Cirera and Maloney, 2017; Forth and Bryson, 2019). Accordingly, they can be viewed as being akin to 'capital' - a pivotal component of the Schumpeterian catch-up process (Cirera and Maloney, 2017). Management capital may be particularly important for firms in emerging markets since they are more likely to face more turbulent market conditions characterised by weak institutions and the absence of sufficient financial intermediaries (Khan et al., 2019).

Furthermore, evidence indicates that firms in most emerging markets display poor management practices relative to those in advanced economies (Bloom et al., 2013; Lemos et al., 2016). More specifically, it has been shown that firms in countries such as India and Pakistan are significantly less likely to have in place any performance monitoring measures or to link pay or promotion with performance (Bloom and Van Reenen, 2007; Damanpour, 2010; Bloom et al., 2012). Evidence suggests that firms fail to adopt new management innovations due to entry barriers, insulation from international competition and high rates of family-ownership and management (Bloom et al., 2013; Lemos et al., 2016; Bloom et al., 2019).

Although studying the factors which may propel firms in emerging markets to adopt new practices is important, it is, nonetheless, a second-order level analysis. The first-order level analysis of why firms in 
emerging markets may choose to learn or acquire new management practices in the first place needs scrutiny as evidence on this issue is scarce. While several studies provide both theoretical and empirical evidence in relation to the nature, determinants and effects of organisational learning of new practices (Lyles, 2016; Szulanski, 1996), few of these studies focus on emerging market firms. In addition, those few studies on emerging markets tend to adopt a partial approach, which considers a small number of antecedents (Bloom and Van Reenen, 2010; Zeng et al., 2019).

Our point of departure in this study is the notion that sufficient absorptive capacity (AC) is the primary determinant of organisational learning of new practices (Strese et al., 2016; Khan et al., 2019; Park and Chung, 2019). AC relates to the ability of the firm to identify and acquire valuable new knowledge and practices (Cohen and Levininthal, 1990; Hart et al., 2016). Knowledge transfer can encompass skills, technology, strategies, and practices that are both tacit and explicit in nature (Lyles, 2016; Kostopoulos et al., 2011). However, in weak institutional contexts, such as those in emerging markets, it is highly likely that other factors may incentivise firms to acquire new business practices besides their absorptive capacity. In particular, the environment in which the firms operate as well as other factors pertaining to the firm itself may be important for the firm's ability and desire to acquire new knowledge (Escribano et al., 2009).

In light of the above, the present study aims to contribute to the literature in two important ways. First, methodologically, we explicitly take into account the issue of model uncertainty by applying Bayesian Model Averaging approach (BMA). In particular, given that theory is vague in relation to the antecedents of the propensity to learn management practices in emerging markets, we have no way of knowing what empirical specification to adopt with certainty. Thus, instead of running the risk of misleading inferences and to minimise the potential of false-positives, we confront model uncertainty head on. Our approach is different from meta analysis, which can be plagued by the "file drawer effect" 
or publication bias (Grewal et al., 2018). Thus, we adopt a more statistically robust approach to identifying the core antecedents of firms' propensity to learn new management practices. The study uses a large dataset on more than 3,600 firm from the South Asian region (Bangladesh, India, Nepal, and Pakistan). In the process, we attempt to fill an important gap in the literature on why some firms in South Asia are more successful in acquiring new management capital while other remain badly managed (Bloom et al., 2013).

Second, we link management practices to both firm-level innovation and performance. We argue that this integrative approach can generate more insights than if either firm performance or innovation is considered separately as the outcome of acquired management practices (Forth and Bryson, 2019). More importantly, we also show that management practices are significant determinant of both potential innovation (i.e. the capacity to innovate) and also actual or realised innovation. As highlighted by Bruhn et al. (2013), the existing literature has mainly linked the weak growth of small and medium enterprises in developing economies to financial impediments, thus, neglecting management practices which can have significant implications for firm strategy, productivity and operational performance (Bloom et al. 2019).

Our findings show that the propensity to learn management practices is principally driven by few factors pertaining to the firm's absorptive capacity (e.g. resource allocation towards internal and external R\&D), characteristics (e.g. whether the firm faces market competition from the informal sector) and the environment in which it operates (e.g. good quality mobile network coverage and the institutional environment). Our results also show that firms with a higher propensity of learning management practices are more likely to become profitable while exhibiting higher levels of both potential and actual innovation. 
The article is structured as follows. The next section sets out the theoretical background and hypothesis development. Section 3 contains a discussion of the data and methods used. Section 4 presents and discusses the results, while the final section provides the conclusion and a discussion of the policy implications.

\section{Theoretical background and research hypotheses}

We postulate that the propensity to learn new management practices is primarily driven by the firm's $\mathrm{AC}$ but also its characteristics and the environment in which it operates. These three components are central to learning orientation, i.e. the commitment to learn new practices and having an organisational culture that is conducive to the pursuit of external knowledge (Rhee et al., 2010). Acquired management practices, in turn, augment the firm's flexibility, responsiveness and productivity and, thus, its profitability and (actual and potential) innovation (Cirera and Maloney, 2017; Bloom et al., 2019).

\subsection{Absorptive capacity (AC) and management practices}

Firms must routinely monitor latest market developments in order to identify market opportunities (Eisenhardt and Martin, 2000; Limaj and Bernroider, 2019). To this end, they need to possess sufficient AC, that is the ability to secure valuable new knowledge and practices (Cohen and Levininthal, 1990). AC has been conceptualised as a multidimensional construct, which captures various capabilities that interact to create value and superior organisational outcomes (Zahra and George, 2002; Wu and Voss, 2015; Strese et al., 2016). These capabilities relate to the ability to acquire, assimilate, transform and exploit external knowledge (Zahra and George, 2002; Strese et al., 2016; Khan et al., 2019). Thus, by internalising and exploiting externally-acquired knowledge, the firm would have a higher probability of invigorating both its knowledge base and also its organisational memory (Strese et al., 2016). 
The AC literature highlights a number of reasons why firms may be interested in acquiring new knowledge and practices. These include the desire to remain competitive and innovative (Xie et al., 2018; Liu et al., 2019; Limaj and Bernroider, 2019). The concept of AC is closely related to knowledge management practices (Strese et al., 2016). These encompass behaviours and strategies that firms use to acquire, transform and apply new knowledge in order to augment their pre-existing pool of explicit and tacit knowledge (Donate and de Pablo, 2015).

Previous studies recognise various forms of valuable external knowledge, including technical and technological skills (Kostopoulos et al., 2011). However, in this paper, we focus on external knowledge relating to management practices which are concerned with operational, organisational, administrative and human resource approaches and processes (Black and Lynch, 2001; Bloom et al., 2010; Bloom et al., 2012; Brynjolfsson and McElheran, 2016; Bloom et al., 2019; Forth and Bryson, 2019). Broadly speaking, management practices incorporate various capabilities that are crucial for higher productivity. Some of these include performance monitoring, just-in-time processes, target setting, long-run planning, feedback mechanisms and people management, including selection and incentive-based policies (Bloom and Van Reenen, 2010; Cirera and Maloney, 2017; Forth and Bryson, 2019). Evidence suggests that management practices are akin to 'capital', in that they are associated with higher productivity (Heyman et al., 2019), profitability (Nieves, 2016), technological innovations (Volberda et al., 2013), improved firm growth and survival rates (Bloom et al., 2019). Thus, 'management capital' is a pivotal component of the Schumpeterian catch-up process (Cirera and Maloney, 2017).

To improve their management practices, firms need to have the means to do so - namely a sufficient AC. In other words, it is AC which empowers firms to recognise, acquire and then assimilate valuable external knowledge vis-à-vis management practices. A firm may rely on local social ties or networks to 
secure this external knowledge, including suppliers, customers, trade associations, workshops, competitors, or professional consultants. Such knowledge transfer may even take place as a result of engagement with business schools or executive training (Bloom et al., 2019). Whatever form this knowledge transfer may take, it involves 'acquisitive learning' as opposed to 'experimental learning', which is knowledge generated within the firm (Dess et al., 2003). Acquisitive learning occurs "when the firm gains access to and subsequently internalizes pre-existing knowledge from its external environment" (Dess et al., 2003, p. 356). This type of interaction and dialogue with the external environment may also be viewed as a form of learning orientation (Rhee et al., 2010). Learning orientation, in turn, can bring about organisational change and can have the potential to influence the firm's strategic behaviours, capabilities and performance (Rhee et al., 2010).

As AC galvanises interactions with the external environment, it is, thus, an important driver of the propensity to acquire new management practices. Nonetheless, to the best of our knowledge, very few studies have been undertaken to examine the factors that incentivise firms in emerging economies to learn new management practices from their external environment. Indeed, the overwhelming majority of studies have looked into why firms adopt new management innovations, which is a second-order level analysis (e.g. Bloom and Van Reenen, 2007; Damanpour, 2010; Bloom et al., 2012). Thus, the firstorder level analysis of why firms may choose to learn new management practices in the first place has been neglected, particularly in emerging economies. Related to this is the need to link the ability to identify the value of new knowledge (i.e. AC) to the propensity to learn new management practices.

On the basis of the above discussion, we postulate that firms with effective knowledge management practices, i.e., having favourable behaviours and strategies and, thus, sufficient AC, would be more likely to acquire new management practices. Consequently, we would expect particular favourable 
behaviours to provide strong indication for effective AC: resource allocation towards internal and external $R \& D$, investments in fixed assets, machinery and equipment, use of foreign-owned licenced technology, and formal staff training as well as opportunity for the purpose of innovative ventures. These behaviours would signify that the firm is committed to the enhancement of its capabilities but also that it has the means of identifying and acquiring external knowledge (i.e. AC). Thus:

H1a: There is a positive relationship between internal $R \& D$ and the acquisition of management practices.

H1b: There is a positive relationship between external R\&D and the acquisition of management practices.

\subsubsection{Firm characteristics and environmental factors}

In ascertaining how $\mathrm{AC}$ affects the acquisition of management practices, it is important to underline that there are other factors that may be related to the propensity of learning new management practices. To this end, we draw on the literature on management innovation and organisational learning. On the basis of this literature, we postulate that the propensity to learn new management practices is also a function of two other broad clusters of antecedents, namely, firm characteristics and environmental factors.

\section{Firm characteristics}

The existing literature emphasises that firms that possess certain attributes are more likely to engage in meaningful learning of new management practices from their external environments. For instance, firm age is potentially an important determinant of organisational learning and innovative behaviour (Jiménez-Jiménez and Sanz-Valle, 2011) as it underpins learning orientation, which includes the acquisition and sharing of useful knowledge that enhances the firm's competitiveness (Calantone et al., 
2002). Since older firms tend to have more deep-rooted and long-established relationships, unlike younger firms, they tend to be more effective in securing innovative ideas (Sinkula, 1994). Similarly, managerial and employee characteristics can influence whether or not firms engage with their external environments (Damanpour and Aravind, 2012; Bloom et al., 2012). Factors such as managers' tenure (i.e. the number of years of experience) and the skills and education of the workforce can have an effect on the propensity to learn, absorb and introduce new innovative management practices (Mol and Birkinshaw, 2009; Damanpour and Aravind, 2012; Bloom et al., 2012).

To the extent that larger firms tend to face more competition whilst possessing larger stock of resources (broadly defined), they are more likely to adopt new practices because they have to do so in order to remain successful but also because they can, due their resource endowments and economies of scope (Mol and Birkinshaw, 2009; Damanpour and Aravind, 2012; Jiménez-Jiménez and Sanz-Valle, 2011). In the same vein, firms that constitute part of a larger enterprise and those with high revenue streams are more likely acquire new information from their external environments (Bloom and Van Reenen, 2010).

Product market competition is one of the most important antecedents of managerial innovation as it tends to force inefficient firms to exit the market whilst rewarding those that acquire, absorb and utilise new knowledge and become efficient with larger share of the market (Bloom and Van Reenen, 2007; Damanpour, 2010; Bloom et al., 2012). Likewise, export-oriented firms tend to display a higher propensity to acquire new management practices simply because they are more likely to form relationships with partners within and outside the domestic market. Also, they tend to face stiffer competition which can encourage the acquisition of new practices (Mol and Birkinshaw, 2009).

Modern technology (e.g. use of emails to communicate) can be an important facilitator of acquisitive learning (Quinton et al., 2018). Consequently, dialogue is necessary for firms to be able to gain access to knowledge from their external environment (Alegre and Chiva, 2008). To the extent that both 
organisational learning and innovative activities can result in negative outcomes in the form of inconvenient changes, employee resistance and higher costs (Simpson et al., 2006), the firm's financial performance, particularly its access to finance, may be important for its appetite to learn new practices. Indeed, firms that are credit-constrained are less likely to obtain finance from conventional banks for initiatives (e.g. organising workshops, hiring consultants) that can increase their acquisition of management practices. According to Bloom et al. (2010) better management practices are not as tangible as physical capital and thus cannot be used as collateral in case of default. Hence, good financial performance and easy access to credit are important determinants of organisational engagement and learning.

In emerging market economies, the formal private sector must overcome the challenges that result from weak institutional environments but also from the unfair competition the informal sector poses as this sector is largely unregulated and is not usually subject to taxes or other administrative burdens (Bloom and Van Reenen, 2010; Williams and Bezeredi, 2018). So stiff market competition, including from the informal sector, is expected to incentivise firms to seek and learn new management practices so as to cement or expand their market share. Accordingly, we pose the following hypothesis:

H2a: There is a positive relationship between market competition and the acquisition of management practices.

H2b: There is a positive relationship between access to finance and the acquisition of management practices.

\section{Environmental factors}

Firms in emerging economies typically face more challenges than their counterparts in advanced economies including different forms of market imperfections (e.g. information asymmetries, weak credit 
markets, property rights, corruption and legal contract enforcement) (Sharma and Mitra, 2015; Chari and Acikgoz, 2016). For example, Bloom et al. (2013) found that one of the main reasons why Indian firms fail to achieve sustained growth is their inability to decentralise decision-making outside family members due to their low confidence in the legal system in the event of a dispute with outside managers. In addition, firms in emerging market economies also tend to be more resource-constrained (broadly defined to include physical, financial and human capital) and the environment in which they operate tends to be more volatile (McKague and Oliver, 2016).

At the same time, we know that the environment in which firms operate is an important determinant of management practices (Bloom et al., 2019). On the one hand, evidence suggests that environmental turbulence can increase risk and uncertainty and thus reduce innovation activities through its adverse influence on future returns (Jiménez-Jiménez and Sanz-Valle, 2011). On the other hand, turbulent business environments can incentivise firms to upgrade their capabilities, become more efficient and innovative (Jiménez-Jiménez and Sanz-Valle, 2011). The environment in which firms operate includes also the availability and quality of infrastructure. As emphasised by Alavi and Leidner (2001), organisations are a form of knowledge systems in which knowledge is created, stored/retrieved, transferred, and subsequently applied so the availability and quality of information technology and mobile network coverage can play a pivotal role in organisational learning of management practices.

In the context of emerging countries, the World Bank Enterprise Surveys (World Bank, 2009) are useful in that they capture different aspects of the business environments in which firms operate. In particular, firms are asked to identify the extent to which a specific issue is an obstacle to their daily operations. The business obstacles captured include corruption, tax regime, telecommunications, courts, labour market regulations, business licensing and permits, crime and theft, access to finance, quality of the labour force, electricity, and political instability. 
Although Bloom et al. (2012) find that restrictive labour market regulations (i.e. the ability to hire, fire, pay and promote) are negatively correlated with innovative management practices, challenging business environments can also be conducive to a higher propensity to learn as organisations attempt to adjust to their hostile surroundings (Jiménez-Jiménez and Sanz-Valle, 2011). Thus, adverse environmental factors influence both management practices and organisational learning but their actual effect is an empirical matter.

Given that firms in emerging countries face higher incidents of institutional weaknesses, it is likely that the quality of institutions matters for organisational learning of management practices. For instance, we expect that weak property rights and legal contract enforcement (e.g. inefficient legal system) can undermine the acquisition of new ideas by increasing uncertainty (Ali, 2013). This may be complicated further by the fact that managerial innovations are more difficult to patent unlike technological innovations (Damanpour and Aravind, 2012). In addition, there is less awareness around the potential of management practices in improving firm productivity and growth (Bloom et al., 2010; Bloom et al., 2019). Accordingly, we explore whether institutional quality explains the variation in organisational learning of management practices across firms by posing the following hypothesis:

H3a: There is a negative relationship between different types of business obstacles and the acquisition of management practices.

H3b: There is a negative relationship between inefficient legal system and the acquisition of management practices.

\subsection{Impact of organisational learning of management practices on firm outcomes}

It is largely accepted that privately-held knowledge can be a fundamental source of competitive advantage (Grant, 1996). Also, firms must continuously upgrade their organisational capabilities, 
processes, and routines in response to market developments secured through the acquisition of external information (Eisenhardt and Martin, 2000). Hence, firms that manage to acquire new management practices are more likely to augment their capabilities and create value due their flexibility and responsiveness (Jiménez-Jiménez and Sanz-Valle, 2011).

According to Cirera and Maloney (2017), there are two main channels through which acquired management practices can lead to higher productivity: a direct effect whereby they facilitate a more efficient use of the factors of production and an indirect effect via increases in the probability of innovation. In particular, favourable management and organisational practices create an environment which is conducive to the transformation of ideas into prototypes and commercial realities (Cirera and Maloney, 2017). Thus, management practices can improve the firm's capacity to innovate and therefore its potential to innovate. In the same vein, management practices are associated with higher output, enabled by better quality control procedures and inventory management, lower machine downtimes and energy use, and more efficient operations (Bloom et al., 2013).

In a seminal contribution, Ichniowski et al. (1997) conducted a detailed study based on firms with similar characteristics and found that the use of practices such as performance pay, and work teams are associated with significant productivity gains. Other studies summarised in Syverson (2011), which use more-detailed production line data have reported similar results (cited in Syverson, 2011). Taken together, the existing evidence suggests that management practices allow firms to be more competitive, productive, profitable and innovative (Mol and Birkinshaw, 2009; Bloom et al., 2010; Bloom et al., 2013; Nieves, 2016; Volberda et al., 2013). Accordingly, we pose the following hypotheses:

H4a: Acquired management practices have positive effects on both potential (i.e. the capacity to innovate) as well as actual innovation. 
H4b: Acquired management practices have positive effect on firm-level performance.

Figure 1 provides an overview of our research model, which consists of a two-stage strategy. In the first stage, we identify the core antecedents of the propensity to learn management practices using various indicators related to the three main clusters of determinants mentioned previously - namely, absorptive capacity, firm characteristics and environmental factors. In the second stage, we relate the propensity to learn management practices to two firm outcomes - namely, firm performance and firm innovation (actual and potential).

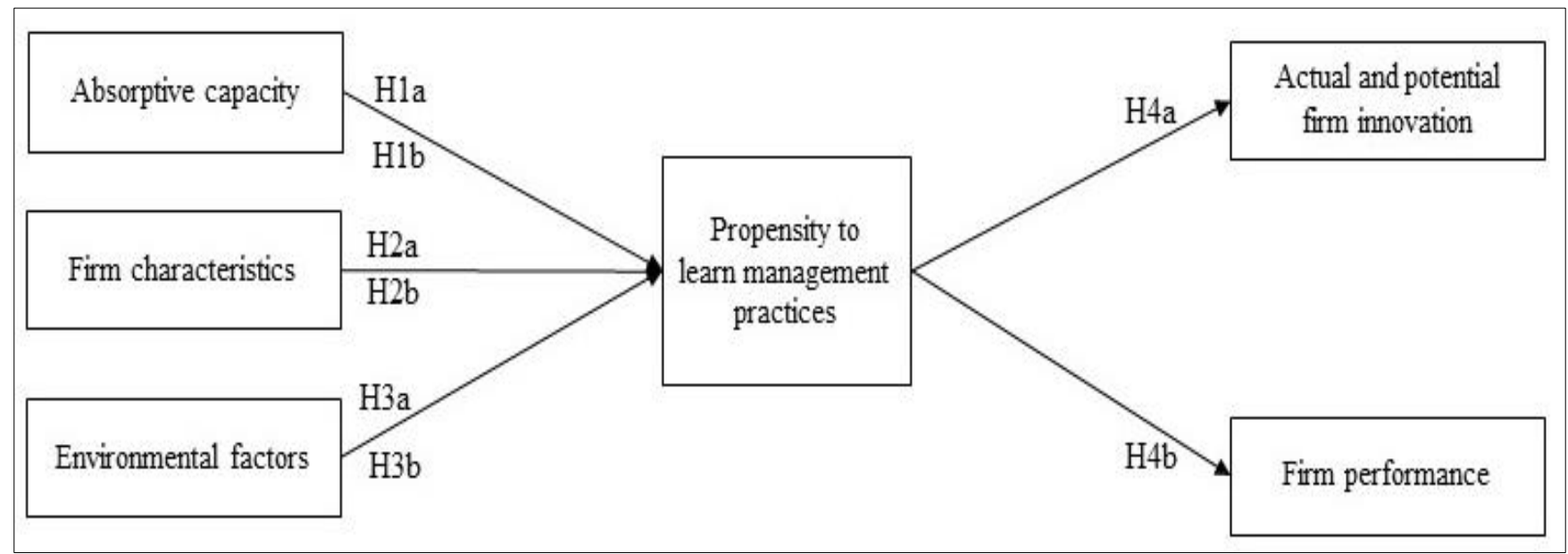

Figure 1: Overview of the research model

\section{Research context and method}

\subsection{Context and dependent variables}

One of our primary objectives in this study is to ascertain the robust drivers of the propensity to acquire management practices, which, as explained above, we relate to the absorptive capacity of firms, their characteristics and the environment in which they operate. Our study is set in four emerging South Asian countries - namely, Bangladesh, India, Nepal and Pakistan. These countries are unique in that the private sector has not yet been able to match the dynamic competitiveness and technological 
advancements of East Asian firms (Shrestha, 2014). In addition, firms operating in these countries have been shown to be poorly managed with adverse consequences for their innovativeness, productivity, competitiveness and operational performance (Bloom et al., 2013; Lemos et al., 2016). Thus, understanding the factors that can enable firms to learn new management practices is a critical issue.

Our main variable of interest (e.g. the acquisition of management practices) comes from the World Bank innovation follow-up survey which was conducted during the period 2013-14 in four South Asian economies (Bangladesh, India, Nepal, and Pakistan) ${ }^{1}$. As the innovation follow up survey covers innovation-related activities, the variables capturing firm absorptive capacity measures also come from this dataset. The other two clusters of antecedents, i.e. firm characteristics and environmental factors are sourced principally from the main World Bank enterprise survey, corresponding to the follow up survey. To capture country-level institutional quality (e.g. property rights protection) and quality of information technology (e.g. mobile network coverage), we use the Global Information Technology Report (GITR) of the same period published by the World Economic Forum (Bilbao-Osorio et al., 2013).

Our dependent variable in the initial stage is "the propensity to learn management practices". To measure this, we draw on a particular question in the innovation follow-up survey, which asks whether the manager(s) did learn management practices from any of the following five different sources of knowledge, namely - suppliers or customers, trade associations or workshops, new employees, competitors, and consultants. As these responses result in 5 binary outcomes ("yes" or "no"), we convert these into a continuous index (i.e. propensity to learn management practices score) that measures the proportion of knowledge sources used by a particular firm. The resulting score has therefore the benefit of falling between 0 and 1 and captures the differential behaviours of firms in relation to learning new management practices. To examine the antecedents of the propensity to learn management practices, we

\footnotetext{
${ }^{1}$ This survey was also conducted in 10 African countries but there are no observations on the acquisition of management practices for the African sample so we cannot conduct any comparative study between African and South Asian firms.
} 
rely on a comprehensive list of 45 variables clustered into three potential antecedents: 1) absorptive capacity indicators (10 variables), firm characteristics (20 variables), and environmental factors (15 variables).

Some of the variables we control for capture some dimensions of firm characteristics such as family and gender. We control for these because evidence suggests that family-owned and owner-managed firms are significantly less inclined to introduce new management practices than those with private equity ownership (Bloom and Van Reenen, 2007; Bloom et al., 2012). Bloom and Van Reenen (2007) highlight two possible reasons for this: 1) management selection from within the family puts a limit on potential talent given that the pool of candidates is relatively small, and 2) the expectation that family members will become managers in the future may cause the so-called "Carnegie effect" in which family members have incentives not to build up a stock of human capital from a young age. In contrast, enterprises that are owned or managed by females seem to display innovative behaviours as they tend to possess favourable characteristics (e.g. resilience) to be able to overcome entry barriers as well as other institutional obstacles (Aterido et al., 2011). Table A1 provides a summary of the definitions of all the variables used.

In the second stage, we relate the propensity to learn management practices to actual firm innovation, proxied by dummy variables coded 1 if the firm has introduced any new products, processes or organisational improvements, and 0 otherwise. We also link it to potential innovation or innovation capacity, which is an index between 0 and 1, capturing how many of the following a particular firm has: a) an internationally-recognised quality certification, b) newly-acquired machinery/software for innovation purposes; and 3) newly-acquired or licensed any patented/non-patented inventions or other types of knowledge for innovation purposes. Finally, we also link to firm performance, which is measured by employment growth. 


\subsection{Research instruments}

As mentioned above, we use secondary data from two sources - namely, the World Bank ${ }^{2}$ and the World Economic Forum. In particular, we use the main World Bank enterprise survey (WBES) and the innovation follow-up survey (IFS). Both surveys cover the same period (2013-2014) and are based on nationally representative samples. The WBES applies standardised survey instruments for cross-country consistency and a sampling framework based on random stratification - namely, firm size, sector, and location (World Bank, 2009). The unit of analysis is the firm and face-to-face interviews are conducted with firm owners and managers. Only the non-agriculture private sector is surveyed and firms employing less than 5 people are not covered to exclude informal firms (World Bank, 2009). To address non-response, the sampling framework incorporates a $25 \%$ safety buffer per stratum and all firms within each stratum have the same probability of being selected. The IFS covers enterprise innovation activities for a subset of the WBES sample and this sample constitutes $75 \%$ of the respondents of the main survey sample (World Bank, 2013).

As firms may face systemic risks (i.e. impacting on all firms) pertaining to the whole business environment within each country, we use two variables from the GITR of the same period published by the World Economic Forum (Bilbao-Osorio et al., 2013). One of these variables captures the extent to which intellectual property protection, including counterfeiting measures are in place while the other captures the extent to which the country's ICT infrastructure is sound (i.e. mobile network coverage).

Even though the original enterprise dataset for the four sample countries contains about 12,456 firms, the sample reduces to 3,676 once we incorporate the IFS and GITR variables. Within each cluster (i.e.

\footnotetext{
${ }^{2}$ www.enterprisesurveys.org
} 
absorptive capacity indicators), we check for multicollinearity to ensure that none of the regressors within each domain can linearly be predicted by the others with a high degree of precision.

\subsection{Econometric modelling}

\section{Bayesian Model Averaging approach and sample selection}

Empirical researchers typically employ a single benchmark model in which a set of explanatory variables are regressed on an outcome variable (Raftery, 1995). As a robustness exercise, researchers subsequently present some variations of the benchmark model and then draw inferences or conclusions based on this single model without explicitly acknowledging the potential issue of model uncertainty (Feldkircher and Zeugner, 2009; Zeugner, 2011; Moral-Benito, 2015). The empirical literature on organisational learning and management practices is no exception. Consequently, in this study, we confront this issue by applying Bayesian Model Averaging (BMA) approach which allows us to consider multiple competing models in a statistically rigorous manner. More specifically, BMA offers a statistically robust selection criterion to identify the robust drivers of the propensity to learn new management practices.

In this paper, we consider the following linear regression model with a constant term $\left(\beta_{0}\right)$ :

$$
y=\beta_{0}+\delta X+\varepsilon
$$

where $y$ is the dependent variable, the propensity to learn new management practices, $\varepsilon$ is a vector of normally distributed $I I D$ error terms with zero mean and variance $\sigma^{2}$, and $X$ is a matrix of 45 regressors clustered into three potential antecedents: 1) absorptive capacity indicators (10 variables), firm characteristics (20 variables), and environmental factors (15 variables) summarised in Table A1. Given

that we have 45 regressors, BMA estimates $2^{45}$ variable combinations (and thus $2^{45}$ models) and takes a weighted average of them. The weights used for the model averaging arise from posterior model 
probabilities (PMPs) based on Bayes' theorem, in which the likelihood of each model is weighted by its prior model probability.

In the context of BMA, we are mainly interested in the posterior inclusion probabilities (PIP) of the explanatory variables, which capture the probability that a particular explanatory variable $(q)$ is included in the "true" model. Thus, the PIP is the sum of PMPs for all the models in which the particular variable $q$ was included:

$$
P I P=p\left(\beta_{q} \neq 0 \mid y, X\right)=\sum_{i=1}^{2^{45}} p\left(M_{i} \mid \beta_{q} \neq 0, y, X\right)
$$

For the regression coefficient $\beta_{i}$, it is standard to adopt the so-called 'Zellner's $g$ prior' where the value of $g$ reflects the degree of prior uncertainty or how much weight is attributed to the prior beliefs of the researcher. Choosing a low g value results in low variance in the prior coefficients, while selecting a large $g$ indicates large variance in the prior coefficients ${ }^{3}$. Zellner's $g$ prior is based on the assumptions that: 1) in each $M_{i}$, the constant and error variance are evenly distributed (as in Eq. 1), and 2) that $\beta_{i}$ coefficients follow a normal distribution with a mean of zero and a variance-covariance structure that is similar to the underlying data. As the coefficient distribution depends on the $g$ prior, Feldkircher and Zeugner (2009) argue in favour of model-specific priors rather than fixed priors that are common to all models. A particular model-specific prior which has been shown to yield more robust estimates is the so-called hyper-g prior, which we use in this paper although our results are robust to different specifications of the parameter priors ${ }^{4}$.

In addition to the priors on the parameter space, prior model probabilities, $P\left(M_{i}\right)$, must be chosen on the model space. In this paper, we use three alternative model priors in order to ensure that our

\footnotetext{
${ }^{3}$ As $g \rightarrow \infty, \beta_{i} \rightarrow \beta_{i}^{\text {OLS }}$

${ }^{4}$ For a detailed discussion on the advantages of 'hyper-g' prior, see Zeugner and Feldkircher (2009).
} 
conclusions are robust. Following, among others, Fernandez et al., (2001) and Hasan et al., (2016), we first apply a 'uniform' model prior. As we have $2^{45}$ possible variable combinations, the uniform model prior implies that each explanatory variable is included in the model with an equal probability of $\omega=1 / 2$ so that all models under consideration have an equal probability of $P\left(M_{i}\right)=2^{-k}$. As emphasised by Zeugner (2011), the uniform model distribution has the weakness of putting more mass around a model size of $k_{i}=k / 2$ given that the combination $\left(\begin{array}{l}k \\ k / 2\end{array}\right)$ would be higher than any other. Thus, as an alternative, we also use a 'fixed' model prior, which puts a common fixed inclusion probability $\omega$ on each explanatory variable. The fixed model prior draws $\omega$ from the binomial distribution and thus the prior probability of a model size $k_{i}$ is given by the product of inclusion and exclusion probabilities as follows:

$$
P\left(M_{i}\right)=\omega^{k_{i}}(1-\omega)^{k-k_{i}}
$$

As the expected value of the model size in Eq. (3) is simply $\bar{m}=k \omega$, the specification of a model size is closely related to the value of $\omega$ as $\omega=\bar{m} / k$. Hence, if one chooses an expected model size of $k / 2$, then this would result in the uniform model prior explained above since the inclusion probability of each regressor will be $\omega=1 / 2$. Consequently, setting the prior model size at a value $>1 / 2$ moves the prior distribution towards a larger model size and vice versa. Following Ley and Steel (2009), we finally use a 'random' model prior which puts a hyperprior on the inclusion probability $\omega$ based on a Beta distribution. As shown by Ley and Steel (2009), this model prior offers considerable flexibility regarding the expected model size and better reflects model uncertainty.

Given that we have 45 covariates, enumerating all possible combinations is computationally challenging as we would have more 35 trillion model combinations. To overcome this, BMA uses a Markov Chain Monte Carlo (MCMC) model sampling tool, which collects results on the most important part of the 
posterior model distribution by 'walking' through the model space. As highlighted by Zeugner (2011), the MCMC is based on the Metropolis-Hastings algorithm and operates as follows: Suppose that an an step $i$, the MCMC sampler is dealing with $M_{i}$ with posterior model probability $P\left(M_{i} \mid y, X\right)$. In the following round, i.e. $i+1$, another candidate model $M_{q}$ is drawn to replace $M_{i}$. The MCMC sampler would accept $M_{q}$ if its marginal likelihood is greater than the marginal likelihood of $M_{i}$. To draw candidate models, we use the birth-death sampler, which randomly chooses a potential regressor to add to $M_{i}$ if it is not already included and drops it if it is already included in $M_{i}$.

Once we have identified the robust drivers of the propensity to learn new management practices using BMA, we employ a number of other econometric models as a sensitivity analysis. Using $i=1,2, \ldots, N$ to index firms, suppose that $L_{i}$ denotes the utility gained from acquiring new management practices by firm $i$ :

$$
L_{i}=\rho Z_{0 i}+u_{0 i}
$$

where $Z_{0 i}$ is a vector of variables that determine the likelihood of learning new management practices, $\rho$ is a vector of coefficients of interest, and $u_{i}$ is an IID error term. Evidently, not all firms engage in organisational learning. Thus, our dependent variable is left censored and is only observed for a subset of the firms - namely, those with $L>0$. As a result, the OLS estimator is likely to yield inconsistent parameters due to potential omitted variable bias that could influence the likelihood of entering the sample (Kennedy, 2008). In an effort to make our findings generalizable to all firms, we employ Heckman's two-stage approach (Heckman, 1979) in which we first estimate a selection equation to generate the inverse Mills ratio (i.e. lambda). We then estimate, in the second stage, the outcome equation based on the OLS estimator using the inverse Mills ratio as an additional independent variable 
to correct for the selection bias (Greene, 2012). However, the OLS estimator is particularly vulnerable to the presence of outliers given that it is based on the minimisation of the variance of the residuals. Thus, as an alternative, we use the so-called MM-estimator originally proposed by Yohai (1987) which is based on a loss function that penalises large residuals and thus is less sensitive to extreme values unlike the variance. As emphasised by Verardi and Croux (2009), the MM-estimator outperforms other available robust estimators as it combines a high breakdown point of $50 \%$ (i.e. can tolerate $50 \%$ of outlier contamination as compared to zero percent in the case of OLS) and a high 95\% Gaussian efficiency.

Finally, recall that we have a continuous dependent variable $y$ in $[0,1]$, and a vector of explanatory variables $(x)$ so we want to fit a regression model for the mean of the dependent variable conditional on the independent variables $E(y \mid x)$. However, unless we restrict the conditional mean $E(y \mid x)$ in $[0,1]$, the estimates could fall outside the unit interval and thus the resulting model may be misspecified (Papke and Wooldridge, 1996; Papke and Wooldridge, 2008). To address this, we follow Papke and Wooldridge who use quasi-maximum likelihood estimation to get robust estimators of the conditional mean coefficients based on the probit mean function: $E(y \mid x)=\Phi(x \beta)$. As shown by Papke and Wooldridge (2008), the resulting fractional response estimator has the advantage of being computationally simple and can handle unobserved heterogeneity/ endogenous independent variables ${ }^{5}$.

\subsection{Robustness: sample selection}

We model the likelihood of acquiring new management practices as a function of four variables: firm size measured as number of employees; total annual costs (wages, salaries, bonuses and social security payments etc.) incurred by firms; 'knowledge capital' proxied by whether the enterprise has abandoned

\footnotetext{
${ }^{5} R$ statistical software and STATA were used in the analysis.
} 
or suspended any innovative ventures during the past year or currently has any ongoing innovative projects; and, top manager's tenure i.e. number of years of experience working in the same sector. Given that larger firms tend to face more competition whilst possessing larger stock of resources (broadly defined), it is expected that they would have a higher probability of learning and adopting new practices because they have to do so in order to remain successful but also because they can, due their resource endowments and economies of scope. Similarly, firms with higher (fixed and variable) costs would, ceteris paribus, be more inclined to seek new ways of achieving higher efficiency. Thus, they would be more likely to learn new practices.

Also, firms with strong 'knowledge capital' in the form of previous and/or ongoing exposure to innovation (even if failing) would be expected to have a high propensity to experiment, take risk and interact with their internal and external environments in order to learn and improve their 'knowledge capital'. Lastly, the top managers' tenure is an important determinant of the decision to learn; experienced managers tend to possess the required skills to be able to acquire, absorb and transform new and existing valuable information. They are also highly likely to have the legitimacy and expertise to be able to galvanise their employees in order to get desired outcomes (Damanpour and Aravind, 2012). Finally, experienced managers have a higher probability of learning innovative management practices simply because they would have had accumulated larger networks over the years. These institutional 'memories' would therefore allow them to have access to a larger pool of contacts to learn from.

\section{Results and discussion}

\subsection{The antecedents of the propensity to learn management practices}

Table 1 presents the estimates of the BMA models based on different model priors. For each model prior, the table reports three statistics - namely, posterior inclusion probability (PIP) which, as we 
defined above, captures how important a given variable is in explaining the dependent variable, the posterior mean of the coefficients (Post mean) averaged over all models, and the posterior standard deviation (Post SD). Using $87 \%$ inclusion probability as a cut-off point across all three model priors, we see that there are 12 robust determinants of the acquisition of management practices, half of these relating to environmental factors. As can be seen, 10 out of these 12 variables have average PIP values above $97 \%$, implying that there is a $97 \%$ probability that these regressors have an effect on the propensity to learn new management practices $^{6}$.

Examining the results more closely, we find that firms with sufficient AC display statistically significant higher propensity of learning new management practices. These results are therefore consistent with H1a and $\mathrm{H} 1 \mathrm{~b}$ as both carry the expected positive sign, which can be seen in the column 'Post Mean'. In particular, they imply that effective knowledge management practices, such as resource allocation towards internal and external $\mathrm{R} \& \mathrm{D}$, provide strong indication that the enterprise is committed to the enhancement of its capabilities. Thus, sufficient AC is a necessary condition for securing valuable management practices.

Similarly, market competition is a significantly robust determinant of the propensity to learn new management practices. Unlike the previous studies, however, our proxy for market competition is specifically concerned with competitive pressures from informal firms. Given that informal firms tend to be largely unregulated and with little or no tax liabilities or other administrative burdens, they can exert substantial competitive pressure on formal firms. These competitive pressures in turn incentivises firms to acquire new management practices in an effort to cement or expand their market share. Thus, $\mathrm{H} 2 \mathrm{a}$ is confirmed.

\footnotetext{
${ }^{6}$ While Raftery (1995) proposes the following PIP thresholds: 0.5-0.75 (weak effect), 0.75-0.95 (positive effect), 0.95 -99 (strong), >0.99 (very strong), others (e.g. Christofides et al., 2016) define PIP values $>0.50$ as “effective". In this paper, we pick the threshold based on where there is "largest" jump in the high end of the PIP values.
} 
The proxies we use for access to finance $(\mathrm{H} 2 \mathrm{~b})$ do not seem to have robust effect on the propensity to learn new management practices with the exception of 'overdraft facility'. Both having 'banking facility' and 'line of credit' have the expected positive signs but both display relatively low PIP values, suggesting they are not robust. In the same vein, the variable 'access to finance as an obstacle' is also insignificant even though it has the expected negative effect. Interestingly, high financial credibility in the form of 'overdraft facility' is associated with a lower probability of learning new management practices - a result, which is highly robust. However, this result does not necessarily imply that firms with access to finance are less likely to acquire new ideas. Rather, it may indicate that firms with high financial credibility may already possess sufficient amount of ideas, including innovative management practices, to be able to convince commercial banks to grant them the overdraft facility.

In addition, firms whose annual financial statements are checked and certified by an external auditor are more likely to acquire management practices. This is to be expected in that external financial scrutiny may act as an effective monitoring devise which can decrease the likelihood of financial statements being manipulated by owners or managers. Also, firms that are run in a 'professional' manner are more likely to be interested in improving their capabilities by reaching out and learning new practices. Perhaps as expected, the propensity of learning new management practices is lower in firms with a high productive efficiency as these firms are already operating at their maximum in terms of capacity.

We use 12 different proxies to test H3a. These proxies capture different aspects of 'business obstacles' but only three of them are robustly related to the propensity to learn new management practices. As expected, as the degree to which telecommunications becomes an obstacle increases, the propensity to learn new management practices decreases. Interestingly, when enterprises perceive the tax regime and corruption as serious impediments to their operations, they are more likely to upgrade their capabilities and increase their organisational learning in an effort to adjust to the hostile environment in which they 
operate. Indeed, by becoming more productive, competitive and profitable through the acquisition of innovative management practices, firms are more likely to absorb the additional costs associated with higher business tax rates and corruption. Hence, it seems that firms tend to react differently to the different business obstacles they face in their day-to-day operations so H3a is partially supported.

We find that intellectual property rights protection has a strong negative effect on the propensity to learn new management practices, confirming H3b. In fact, this variable has the largest (mean) coefficient of all the variables under consideration, with a value of around -0.164 in the case of our preferred (random) model prior. This suggests that a strong private intellectual property regime tends to encourage economic agents to shy away from adopting management innovations devised by others in fear of potential legal ramifications. This might seem at odds with the widely-held view within the literature that management practices are not as tangible, and thus more difficult to patent, as other types of innovations (see for example, Damanpour and Aravind, 2012). However, we argue that this result should be seen in the context of South Asian countries where firms tend to be much more resource-constrained whilst, at the same time, facing institutional weaknesses, including weakly defined property rights and legal contract enforcement. Thus, in this scenario, it makes sense for firms to 'play safe'. Indeed, our results also show that the more firms believe the court system to be unfair, partial and corrupted (i.e. inefficient legal system) the more likely they are to reduce their propensity to learn new management practices (H3b). Accordingly, these two findings should be viewed together as they are closely connected.

Finally, consistent with the view that modern technology is an important facilitator of acquisitive learning and that information communication technology (ICT) underpins firms as a form of knowledge systems, we find that high quality mobile network coverage has a significant positive influence on the propensity to learn new management practices. 
While the remaining 33 regressors are not robustly related to the propensity to learn new management practices given their PIP values, there are a number of interesting findings: female-managed firms seem to display a high propensity to learn new management practices. This is consistent with the results reported elsewhere in terms of females being, on average, more innovative (Aterido et al., 2011). Similarly, firms with pro-innovation organisational culture and those with a high resource allocation towards innovative activities are more likely to engage in organisational learning (Adams et al., 2006).

\subsection{Sample selection results}

Panel A of Table 2 summarises the results of the Heckman selection model. The results indicate that the probability of learning new management practices for a typical enterprise increases with the size, costs, and knowledge capital of the firm. In line with the existing literature, we also find that the top managers' tenure is an important determinant of the likelihood of acquiring new management practices. All four variables are statistically significant at conventional levels and their signs are consistent with our a priori expectations.

The results of the outcome equation which captures the effects of the robust determinants on the propensity to learn new management practices, as identified by the BMA approach above, are shown in Panel B of Table 2. The first thing to note is that the inverse Mills ratio (lambda) is highly statistically significant across all the regressions, implying that there is a sample selection bias. Thus, Heckman's two-step estimator is appropriate to overcome this issue. The results of the full sample are consistent with the BMA results in terms of both sign and significance.

\subsection{The impact of the propensity to learn on firm innovation and growth}

The existing body of evidence is largely supportive of the view that organisational learning of new practices is positively related to firm-level innovation and performance through its significant effects on 
the dynamic capabilities of the firm (Jiménez-Jiménez and Sanz-Valle, 2011; Alegre and Chiva, 2008). Also, organisational learning is believed to enhance firm productivity, efficiency and competiveness. In this section, we attempt to verify these assertions by augmenting standard firm-innovation and performance regressions with our measure of the acquisition of new management practices.

The results of the impact of organisational learning of new management practices on innovation is summarised in Table 3. Controlling for innovation effort (i.e. spending on fixed assets and R\&D), firmspecific factors (i.e. export orientation, firm age and size), the environment in which firms operate (i.e. business obstacles), industry characteristics and sample selection, we find that the acquisition of new management practices has a significant positive influence on the probability of firms being innovative (H4a). As our variable of interest lies between 0 and 1, its coefficient indicates the impact of nonengagement to full-engagement in terms of learning new practices. Thus, for instance, learning management practices from all potential sources of knowledge (e.g. suppliers, customers, trade associations, workshops etc.) is estimated to increase the probability of product innovation by about 0.063 to 0.089 relative to not learning any new practices at all. The probability is a bit higher for process and organisational innovation as well as for innovation capacity. In the same vein, as can be seen in Table 4, acquiring new management practices is positively and significantly related to firm performance, controlling for the standard determinants of firm growth (H4b).

In summary, we find that the propensity to learn new management practices by South Asian firms is principally driven by relatively small number of factors. More specifically, firms that allocate increased resources towards internal and external $R \& D$ and those that face increased market competition are more likely to display a higher propensity to learn new management practices. The results in relation to business obstacles are mixed; while firms that perceive the tax regime and corruption as serious impediments to their operations are more likely to learn new practices perhaps in an effort to absorb 
additional costs, firms that consider telecommunications as an obstacle are significantly less likely to learn new practices. Similarly, firms that perceive the legal system as inefficient are significantly less likely to learn when it comes to management practices. However, access to finance does not have the expected positive influence on learning. Lastly, higher propensity to learn new management practices has significant positive effects on both firm innovation and growth.

\section{Table 5: Summary of hypotheses tests}

\begin{tabular}{|c|c|c|c|}
\hline Antecedents & Hypotheses & Coefficient & Conclusion \\
\hline \multirow[t]{2}{*}{ Absorptive capacity (AC) } & H1a: internal R\&D $\rightarrow$ the acquisition of management practices $(+)$ & $1.000^{\#}(+)$ & Support \\
\hline & H1b: external R\&D $\rightarrow$ the acquisition of management practices $(+)$ & $0.997^{\#}(+)$ & Support \\
\hline \multirow[t]{2}{*}{ Firm characteristics } & H2a: market competition $\rightarrow$ the acquisition of management practices $(+)$ & $0.999^{\#}(+)$ & Support \\
\hline & $\mathrm{H} 2 \mathrm{~b}$ : access to finance $\rightarrow$ the acquisition of management practices $(+)$ & $0.152^{\#}(-)$ & No support \\
\hline \multirow[t]{2}{*}{ Environmental factors } & H3a: business obstacles $\rightarrow$ the acquisition of management practices (-) & $\square$ & Partial support \\
\hline & H3b: inefficient legal system $\rightarrow$ the acquisition of management practices (-) & $0.872^{\#}(-)$ & Support \\
\hline \multirow[t]{3}{*}{ Management practices } & H4a: management practices $\rightarrow$ firm-level innovation $(+)$ & $0.105^{* * *}(+)$ & Support \\
\hline & & $0.072^{* * *}(+)$ & \\
\hline & H4b: management practices $\rightarrow$ firm performance $(+)$ & $3.417^{\# \#}(+)$ & Support \\
\hline
\end{tabular}

Notes: The 'coefficient' column summarises the relevant results from Tables $1,3 \& 4$. ${ }^{\text {\# }}$ Based on the PIP values of our preferred random model prior. ${ }^{\square}$ Mixed results: both corruption and tax regime as obstacles carry PIP values of 1.000 and positive signs while telecom as an obstacle carries the expected negative sign $(\mathrm{PIP}=0.966) .{ }^{* * *}$ Based on the average beta value of management practices in columns $1-6$, and 7 - 8 of Panel B of Table 3. ${ }^{\# \#}$ Based the average beta value of management practices in Table 4.

This study furthers our understanding of the factors that facilitate the acquisition of management practices by firms in emerging markets. Consistent with Bloom and Van Reenen (2007), Damanpour (2010) and Bloom et al., (2012), we find that market competition is a significant determinant of organisational learning. We posit that market competition incentivises firms to acquire new knowledge so as to survive and remain in the market place. Our empirical findings also support the notion that firms that engage in internal and external $\mathrm{R} \& \mathrm{D}$ are more likely to learn new practices. This implies that possessing sufficient AC (e.g. devoting resources to innovation-related activities) is a way for firms to augment their pool of explicit and tacit knowledge (Donate and de Pablo, 2015). 
The inclusion of factors relating to the business environment underlines the fact that firms can react differently to the various business obstacles they face in their day-to-day operations. This heterogeneity tends to be missed in the literature (Huynh et al., 2016). Obstacles relating to the efficiency of the legal system and telecommunication are found to be particularly detrimental to organisational learning of management practices. Interestingly, environmental turbulence in the form of higher incidence of corruption is associated with higher organisational learning. This is consistent with the 'greasing the wheels' hypothesis, which argues that firms may use corruption to overcome the adverse effects of disruptive environments (Dreher and Gassebner, 2013).

We provide empirical evidence showing that the acquisition of new management practices has significant positive effects on firm performance. This is expected as these practices incorporate crucial capabilities, including performance and people management (i.e. target setting, feedback, selection, incentives), and operational factors (i.e. planning, justin-time processes). This finding is in line with previous research which linked organisational learning and management practices to firm growth and profitability (Nieves, 2016; Bloom et al., 2019). Similarly, consistent with Volberda et al., (2013), we show that organisational learning of new management practices is associated with different types of innovations. Finally, our results indicate that management practices can indeed improve the innovation capacity of firms, as shown in Table 3.

\section{Conclusions, recommendations and limitations}

A vibrant private sector is needed for economic development to take root and for society to prosper (Cirera and Maloney, 2017). Unfortunately, firms in South Asian countries tend to be poorly managed with adverse consequences for their innovativeness, productivity, competitiveness and operational 
performance (Bloom et al., 2013; Lemos et al., 2016). Thus, understanding the factors that can enable firms to learn new management practices is a critical issue.

Applying Bayesian Model Averaging (BMA) approach, we investigate the main determinants of the propensity of firms to learn innovative management practices in emerging South Asian firms. Given that we know little on this issue, in spite of the considerable literature on organisational learning and management innovation, we employ BMA to take into account the issue of model uncertainty. The BMA estimations are based on different priors both on the parameter space as well as on the model space to ensure robustness of the estimates. Other methodological issues such as sample selection bias and model misspecification are also confronted.

Using 45 regressors clustered into three potential antecedents, the results indicate that there are 12 robust determinants of the propensity to learn new management practices. These variables are deemed to be the most significant determinants as they display a high posterior inclusion probability close to $90 \%$ across the different model priors. On the whole, the study uncovers some important antecedents of management practices; market competition, resource allocation towards internal and external $\mathrm{R} \& \mathrm{D}$, good quality mobile network coverage and the use of external certified financial auditors are all positively and significantly correlated with organisational learning of management practices. The findings also show that private intellectual property rights protection in the context of inefficient legal systems can deter firms from learning, perhaps in fear of legal ramifications. As the degree to which telecommunications becomes an obstacle increases, the propensity to learn new management practices decreases. The results also suggest that challenging business environments with high tax and corruption incidences can encourage firms to acquire new business practices, perhaps in an effort to upgrade their capabilities and become more competitive in order to adjust to the increasing costs these would entail. Finally, the study 
shows that firms with a higher propensity of learning management practices are more likely to become profitable while displaying higher levels of both potential and actual innovation.

In conclusion, this paper is the first systematic attempt to understand the significant drivers of the propensity to learn new management practices and how these in turn impact on both firm performance and innovation. We argued throughout that the acquisition of new practices can play a pivotal role in augmenting firms' capabilities. We also contended that the propensity to learn management practices is principally driven by few factors pertaining to the firm's absorptive capacity, characteristics and the environment in which it operates.

\subsection{Policy and managerial implications}

The findings of this study call for a number of important policy prescriptions for developing economies. First, there should be an increased awareness of the potential benefits of innovative management practices and managers or administrators should be encouraged to acquire them by, for example, engaging with their stakeholders, professional and social networks, attending workshops, and hiring consultants etc. This is because firms with a higher propensity of learning management practices are more likely to become innovative and profitable, as this study has shown. In turn, innovative and high performing firms are more likely to contribute to the process of economic development. Second, developing countries should invest in high quality ICT infrastructure including reliable mobile network coverage for two main reasons: 1) good ICT enables firms to function as knowledge systems where valuable information is created, stored and applied, and 2) acquisitive organisational learning relies heavily on having dialogue and interactions with others. Finally, the quality of political, legal and economic institutions should be enhanced as these are necessary preconditions for strong credit markets, property rights, and legal contract enforcement. In the absence of these, the environment in which firms operate can become an impediment to a vibrant and dynamic private sector. 
The main managerial implication emanating from this study is that managers should recognise the importance of privately-held information. More specifically, they should strategically tap into the valuable knowledge and know-how in relation to management practices that may be secured from, among others, their suppliers and competitors. This would make them more innovative and profitable.

\subsection{Limitations and future research}

Even though we have attempted to address methodological issues such as model uncertainty, sample selection and unobserved heterogeneity, our study has some limitations which future research could attempt to overcome. First, the dataset we use is cross-section in nature which makes addressing things such as causality and simultaneity difficult. Second, most of the explanatory variables we use are perception-type measures. Given this, our findings might suffer from common method bias. Third, the way our main variable of interest - namely, organisational learning of management practices, is operationalised has the weakness that it does not take into account the intensity of the relationship the firm has with those it is learning from. Finally, it does not capture the extent to which firms internalise the acquired management practices sufficiently. To address these final two points (i.e. the intensity of the relationship and the internalisation of the acquired business practices), future research could perhaps draw on the work of Kreiser (2011), who posits that acquisitive and excremental learning are facilitated by "network range" and "network closure". The first is concerned with the number of distinctive networks with which a firm is directly connected while the latter refers to the extent to which these ties are strong or not. These could then be operationalised using, for example, a Likert scale.

Lastly, it is hoped that this paper and its content will motivate future research into how firms in developing countries can improve their management practices. In this way, firms would have a higher chance of contributing more positively to the process of economic development. 


\section{References}

Adams, R., Bessant, J. and Phelps, R., 2006. Innovation management measurement: A review. International Journal of Management Reviews, 8(1), pp.21-47.

Alavi, M. and Leidner, D.E., 2001. Knowledge management and knowledge management systems: Conceptual foundations and research issues. MIS Quarterly, 25(1).pp.107-136.

Alegre, J. and Chiva, R., 2008. Assessing the impact of organizational learning capability on product innovation performance: An empirical test. Technovation, 28(6), pp.315-326.

Ali, A., 2013. Are property rights institutions and financial development complements or substitutes? The case of private investment. Economics Bulletin, 33(2), pp.1126-1131.

Aterido, R., Beck, T., and Iacovone, L. 2011. Gender and finance in Sub-Saharan Africa: Are women disadvantaged? Policy Research Working Paper WPS 5571. Washington, DC: World Bank.

Bilbao-Osorio, B., Dutta, S., Lanvin, B., 2013. The Global Information Technology Report 2014. Rewards and Risks of Big Data. World Economic Forum and INSEAD, Geneva.

Black, S.E. and Lynch, L.M., 2001. How to compete: the impact of workplace practices and information technology on productivity. Review of Economics and Statistics, 83(3), pp.434-445.

Bloom, N. and Van Reenen, J., 2007. Measuring and explaining management practices across firms and countries. The Quarterly Journal of Economics, 122(4), pp.1351-1408.

Bloom, N. and Van Reenen, J., 2010. Why do management practices differ across firms and countries? Journal of Economic Perspectives, 24(1), pp.203-24.

Bloom, N., Eifert, B., Mahajan, A., McKenzie, D. and Roberts, J., 2013. Does management matter? Evidence from India. The Quarterly Journal of Economics, 128(1), pp.1-51.

Bloom, N., Genakos, C., Sadun, R. and Van Reenen, J., 2012. Management practices across firms and countries. The Academy of Management Perspectives, 26(1), pp.12-33. 
Bloom, N., Mahajan, A., McKenzie, D. and Roberts, J., 2010. Why do firms in developing countries have low productivity? The American Economic Review, 100(2), pp.619-623.

Bloom, N., Sadun, R., Lemos, R. and Reenen, J.V., 2019. Healthy business? Managerial education and management in healthcare. Review of Economics and Statistics, pp.1-45.

Bruhn, M., Karlan, D.S. and Schoar, A., 2013. The impact of consulting services on small and medium enterprises: Evidence from a randomized trial in Mexico. Policy Research Working Paper Series 6508. The World Bank.

Brynjolfsson, E. and McElheran, K., 2016. The rapid adoption of data-driven decision-making. American Economic Review, 106(5), pp.133-39.

Calantone, R.J., Cavusgil, S.T. and Zhao, Y., 2002. Learning orientation, firm innovation capability, and firm performance. Industrial Marketing Management, 31(6), pp.515-524.

Chari, M. and Acikgoz, S., 2016. What drives emerging economy firm acquisitions in tax havens? Journal of Business Research, 69(2), pp.664-671.

Cirera, X. and Maloney, W.F., 2017. The innovation paradox: Developing-country capabilities and the unrealized promise of technological catch-up. The World Bank.

Cohen, W.M. and Levinthal, D.A., 1990. Absorptive capacity: A new perspective on learning and innovation. Administrative Science Quarterly, 35(1), pp.128-152.

Damanpour, F. and Aravind, D., 2012. Managerial innovation: Conceptions, processes, and antecedents. Management and Organization Review, 8(2), pp.423-454.

Damanpour, F., 2010. An integration of research findings of effects of firm size and market competition on product and process innovations. British Journal of Management, 21(4), pp.996-1010.

Dess, G.G., Ireland, R.D., Zahra, S.A., Floyd, S.W., Janney, J.J. and Lane, P.J., 2003. Emerging issues in corporate entrepreneurship. Journal of Management, 29(3), pp.351-378. 
Donate, M.J. and de Pablo, J.D.S., 2015. The role of knowledge-oriented leadership in knowledge management practices and innovation. Journal of Business Research, 68(2), pp.360-370.

Dreher, A. and Gassebner, M., 2013. Greasing the wheels? The impact of regulations and corruption on firm entry. Public Choice, 155 (3-4), pp. 413-432.

Eisenhardt, K.M. and Martin, J.A., 2000. Dynamic capabilities: what are they? Strategic Management Journal, 21(10-11), pp.1105-1121.

Escribano, A., Fosfuri, A. and Tribó, J.A., 2009. Managing external knowledge flows: The moderating role of absorptive capacity. Research Policy, 38(1), pp.96-105.

Feldkircher, M. and Zeugner, S., 2009. Benchmark Priors Revisited: On Adaptive Shrinkage and the Supermodel Effect in Bayesian Model Averaging. Working Paper 09/202 International Monetary Fund.

Fernandez, C., Ley, E. and Steel, M.F., 2001. Model uncertainty in cross- country growth regressions. Journal of Applied Econometrics, 16(5), pp.563-576.

Forth, J. and Bryson, A., 2019. Management practices and SME performance. Scottish Journal of Political Economy., 66(4), pp. 527-58.

Grant, R.M., 1996. Toward a knowledge- based theory of the firm. Strategic Management Journal, 17(S2), pp.109-122.

Greene, W. H., 2012. Econometric analysis, 7th Edition. Pearson

Grewal, D., Puccinelli, N. and Monroe, K.B., 2018. Meta-analysis: integrating accumulated knowledge. Journal of the Academy of Marketing Science, 46(1), pp.9-30.

Hart, T.A., Gilstrap, J.B. and Bolino, M.C., 2016. Organizational citizenship behavior and the enhancement of absorptive capacity. Journal of Business Research, 69(10), pp.3981-3988. 
Hasan, I., Horvath, R. and Mares, J., 2016. What type of finance matters for growth? Bayesian model averaging evidence. The World Bank Economic Review, 32(2), pp. 383-409.

Heckman, J. 1979. Sample selection bias as a specification error. Econometrica, 47(1), pp. 153-61.

Heyman, F., Norbäck, P.J. and Hammarberg, R., 2019. Foreign direct investment, source country heterogeneity and management practices. Economica, 86(342), pp.362-395.

Huynh, K.P., Jacho-Chavez, D.T., Kryvtsov, O., Shepotylo, O. and Vakhitov, V., 2016. The evolution of firm-level distributions for Ukrainian manufacturing firms. Journal of Comparative Economics, 44(1), pp.148-162.

Ichniowski, C., Shaw, K. and Prennushi, G., 1997. The effects of human resource practices on manufacturing performance: A study of steel finishing lines. American Economic Review, 87(3), pp.291-313.

Jiménez-Jiménez, D. and Sanz-Valle, R., 2011. Innovation, organizational learning, and performance. Journal of Business Research, 64(4), pp.408-417.

Kennedy, P., 2008. A guide to Econometrics. 6th Edition. MIT Press.

Khan, Z., Lew, Y.K. and Marinova, S., 2019. Exploitative and exploratory innovations in emerging economies: The role of realized absorptive capacity and learning intent. International Business Review, 28(3), pp.499-512.

Kostopoulos, K., Papalexandris, A., Papachroni, M. and Ioannou, G., 2011. Absorptive capacity, innovation, and financial performance. Journal of Business Research, 64(12), pp.1335-1343.

Kreiser, P.M., 2011. Entrepreneurial orientation and organizational learning: The impact of network range and network closure. Entrepreneurship Theory and Practice, 35(5), pp.1025-1050. 
Lemos, R., Choudhury, A., Van Reenen, J. and Bloom, N., 2016. Management in Pakistan: First evidence from Punjab. International Growth Centre Working Paper (March). The London School of Economics.

Ley, E. and Steel, M.F., 2009. On the effect of prior assumptions in Bayesian model averaging with applications to growth regression. Journal of Applied Econometrics, 24(4), pp.651-674.

Limaj, E. and Bernroider, E.W., 2019. The roles of absorptive capacity and cultural balance for exploratory and exploitative innovation in SMEs. Journal of Business Research, 94, pp.137-153.

Liu, Y., Chan, C., Zhao, C. and Liu, C., 2019. Unpacking knowledge management practices in China: do institution, national and organizational culture matter? Journal of Knowledge Management, 23(4), pp.619-643.

Lyles, M., 2016. Leveraging organizational learning and alliances in complex and changing business environments. Global Entrepreneurship: Past, Present \& Future (Advances in International Management) 29. Emerald Group Publishing Limited, pp. 5-17.

McKague, K. and Oliver, C., 2016. Network bricolage as the reconciliation of indigenous and transplanted institutions in Africa. Africa Journal of Management, 2(3), pp.300-329.

Mol, M.J. and Birkinshaw, J., 2009. The sources of management innovation: When firms introduce new management practices. Journal of Business Research, 62(12), pp.1269-1280.

Moral- Benito, E., 2015. Model averaging in economics: An overview. Journal of Economic Surveys, 29(1), pp.46-75.

Nieves, J., 2016. Outcomes of Management Innovation: An Empirical Analysis in the Services Industry. European Management Review, 13(2), pp.125-136.

Papke, L.E. and Wooldridge, J.M., 1996. Econometric methods for fractional response variables with an application to 401(k) plan participation rates. Journal of Applied Econometrics, 11(6), pp.121-133. 
Papke, L.E. and Wooldridge, J.M., 2008. Panel data methods for fractional response variables with an application to test pass rates. Journal of Econometrics, 145(1), pp.121-133.

Park, H. and Chung, C.C., 2019. The role of subsidiary learning behavior and absorptive capacity in foreign subsidiary expansion. International Business Review, 28(4), pp.685-695.

Quinton, S., Canhoto, A., Molinillo, S., Pera, R. and Budhathoki, T., 2018. Conceptualising a digital orientation: antecedents of supporting SME performance in the digital economy. Journal of Strategic Marketing, 26(5), pp.427-439.

Raftery, A.E., 1995. Bayesian model selection in social research. Sociological Methodology, 25 pp.111163.

Rhee, J., Park, T. and Lee, D.H., 2010. Drivers of innovativeness and performance for innovative SMEs in South Korea: Mediation of learning orientation. Technovation, 30(1), pp.65-75.

Sharma, C. and Mitra, A., 2015. Corruption, governance and firm performance: Evidence from Indian enterprises. Journal of Policy Modeling, 37(5), pp.835-851.

Shrestha, P.K., 2014. Economic development in South and East Asia: empirical examination of East Asian development model. Asia-Pacific Development Journal, 20(2), pp.1-28.

Simpson, P.M., Siguaw, J.A. and Enz, C.A., 2006. Innovation orientation outcomes: The good and the bad. Journal of Business Research, 59(10), pp.1133-1141.

Sinkula, J.M., 1994. Market information processing and organizational learning. The Journal of Marketing, 58(1) pp.35-45.

Strese, S., Adams, D.R., Flatten, T.C. and Brettel, M., 2016. Corporate culture and absorptive capacity: The moderating role of national culture dimensions on innovation management. International Business Review, 25(5), pp.1149-1168.

Syverson, C., 2011. What determines productivity? Journal of Economic literature, 49(2), pp.326-65. 
Szulanski, G., 1996. Exploring internal stickiness: Impediments to the transfer of best practice within the firm. Strategic Management Journal, 17(S2), pp.27-43.

Verardi, V. and Croux, C., 2009. Robust regression in Stata. Stata Journal, 9 (3), pp. 439-453

Volberda, H.W., Van Den Bosch, F.A. and Heij, C.V., 2013. Management innovation: Management as fertile ground for innovation. European Management Review, 10(1), pp.1-15.

Williams, C.C. and Bezeredi, S., 2018. Evaluating the impact of informal sector competition on firm performance: Some lessons from South-East Europe. Journal of Developmental Entrepreneurship, 23(04), p.1850025.

World Bank. 2009. Enterprise survey and indicator surveys - sampling methodology. Available at: www.enterprisesurveys.org

World Bank. 2013. Innovation Follow-up Survey. Ref. PAK_2013_ES-INNOV_v01_M. Available at: https://microdata.worldbank.org/index.php/catalog/2266

Wu, A. and Voss, H., 2015. When does absorptive capacity matter for international performance of firms? Evidence from China. International Business Review, 24(2), pp.344-351.

Xie, X., Zou, H. and Qi, G., 2018. Knowledge absorptive capacity and innovation performance in hightech companies: A multi-mediating analysis. Journal of Business Research, 88, pp.289-297.

Yohai, V.J., 1987. High breakdown-point and high efficiency robust estimates for regression. The Annals of Statistics, 15(2) pp.642-656.

Zahra, S.A. and George, G., 2002. Absorptive capacity: A review, reconceptualization, and extension. Academy of Management Review, 27(2), pp.185-203.

Zeng, J., Glaister, K.W. and Darwish, T., 2019. Processes Underlying MNE Subsidiary Absorptive Capacity: Evidence from Emerging Markets. Management International Review, pp.1-31.

Zeugner, S., 2011. Bayesian model averaging with BMS. Tutorial to the R-package BMS 1e30. 
Table A1 Description of variables

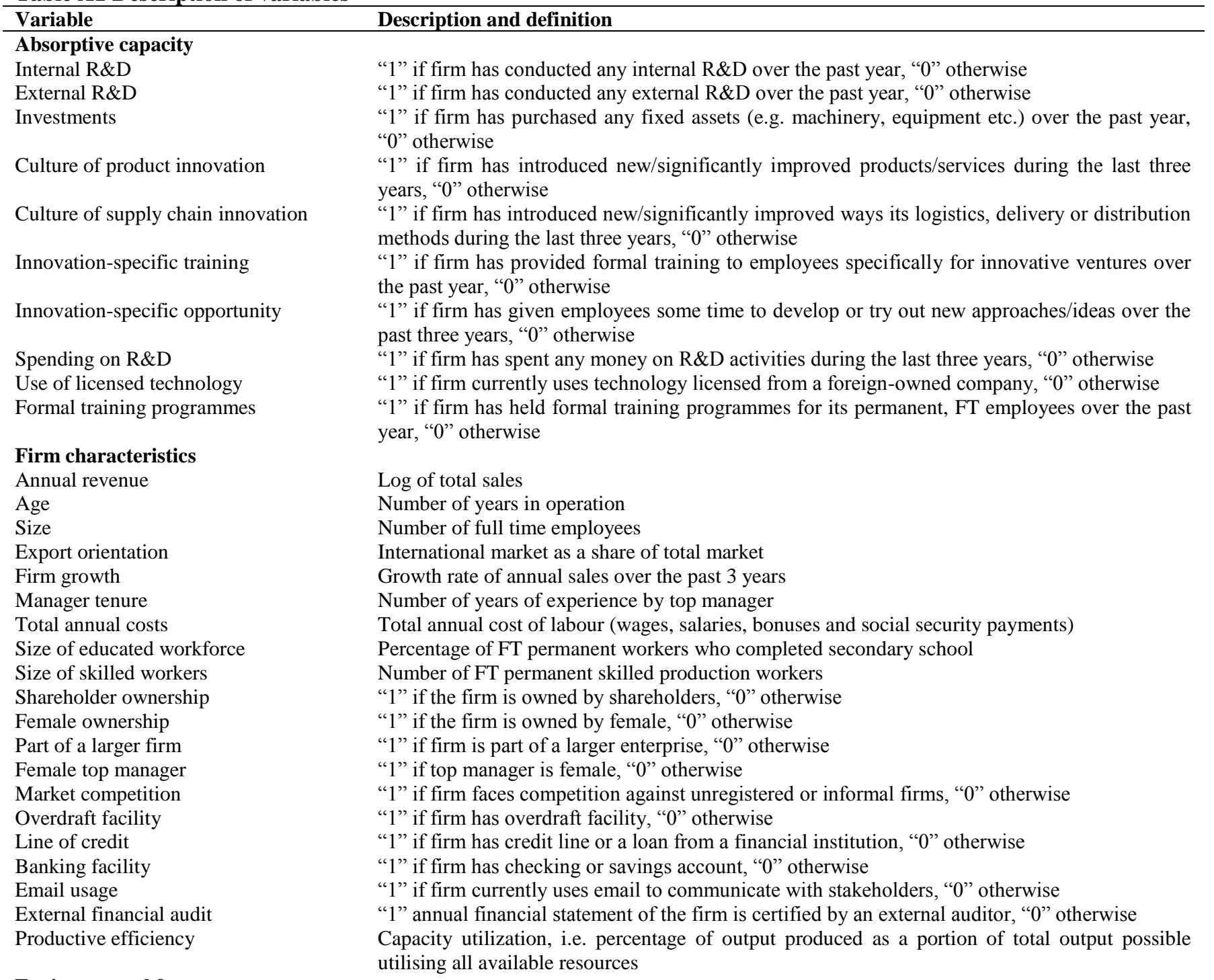

\section{Environmental factors}

Quality of workforce as an obstacle Labour regulation as an obstacle Business licensing as an obstacle Access to finance as an obstacle Political instability as an obstacle Access to land as an obstacle Crime \& theft as an obstacle Tax regime as an obstacle Corruption as an obstacle Electricity as an obstacle Telecom as an obstacle Courts as an obstacle Intellectual property protection

Mobile network coverage Inefficient legal system

Measured on a scale of $0-4$ ( 0 being no obstacle and 4 being a very severe obstacle) Measured on a scale of $0-4$ ( 0 being no obstacle and 4 being a very severe obstacle) Measured on a scale of $0-4$ ( 0 being no obstacle and 4 being a very severe obstacle) Measured on a scale of $0-4$ ( 0 being no obstacle and 4 being a very severe obstacle) Measured on a scale of $0-4$ ( 0 being no obstacle and 4 being a very severe obstacle) Measured on a scale of $0-4$ ( 0 being no obstacle and 4 being a very severe obstacle) Measured on a scale of $0-4$ ( 0 being no obstacle and 4 being a very severe obstacle) Measured on a scale of $0-4$ ( 0 being no obstacle and 4 being a very severe obstacle) Measured on a scale of $0-4$ ( 0 being no obstacle and 4 being a very severe obstacle) Measured on a scale of $0-4$ ( 0 being no obstacle and 4 being a very severe obstacle) Measured on a scale of $0-4$ ( 0 being no obstacle and 4 being a very severe obstacle) Measured on a scale of $0-4$ ( 0 being no obstacle and 4 being a very severe obstacle) The extent to which the regulatory environment facilitates the development of business activities, measured on a 1-to7 (best) scale.

The extent to which the country's ICT infrastructure is good, measures network coverage as \% of population.

Whether firms believe the court system to be fair, impartial and uncorrupted, measured on a scale of $0-3$ ( 0 being strongly agree and 3 being strongly disagree) 
Table 1 The determinants of the propensity to learn new management practices - estimations based on different model priors

\begin{tabular}{|c|c|c|c|c|c|c|c|c|c|}
\hline \multirow[t]{2}{*}{ Variable } & \multicolumn{3}{|c|}{ Mprior=Uniform } & \multicolumn{3}{|c|}{ Mprior=Random } & \multicolumn{3}{|c|}{ Mprior=Fixed } \\
\hline & PIP & Post Mean & Post SD & PIP & Post Mean & Post SD & PIP & Post Mean & Post SD \\
\hline Intellectual property rights protection & 1.000 & -0.163 & 0.015 & 1.000 & -0.164 & 0.015 & 1.000 & -0.164 & 0.015 \\
\hline Tax regime (as an obstacle) & 1.000 & 0.028 & 0.006 & 1.000 & 0.028 & 0.006 & 1.000 & 0.028 & 0.006 \\
\hline Internal R\&D & 1.000 & 0.056 & 0.012 & 1.000 & 0.057 & 0.012 & 1.000 & 0.056 & 0.012 \\
\hline Mobile network coverage & 1.000 & 0.006 & 0.000 & 1.000 & 0.006 & 0.000 & 1.000 & 0.006 & 0.000 \\
\hline Market competition & 1.000 & 0.049 & 0.012 & 0.999 & 0.049 & 0.012 & 0.999 & 0.049 & 0.012 \\
\hline Corruption (as an obstacle) & 0.999 & 0.025 & 0.005 & 1.000 & 0.025 & 0.005 & 1.000 & 0.025 & 0.005 \\
\hline External R\&D & 0.999 & 0.073 & 0.018 & 0.997 & 0.073 & 0.018 & 0.998 & 0.073 & 0.018 \\
\hline Productive efficiency & 0.987 & -0.001 & 0.000 & 0.985 & -0.001 & 0.000 & 0.993 & -0.001 & 0.000 \\
\hline Overdraft facility & 0.974 & -0.042 & 0.014 & 0.955 & -0.041 & 0.015 & 0.975 & -0.042 & 0.014 \\
\hline Telecom (as an obstacle) & 0.974 & -0.024 & 0.008 & 0.966 & -0.024 & 0.009 & 0.977 & -0.024 & 0.008 \\
\hline Inefficient legal system & 0.893 & -0.016 & 0.008 & 0.872 & -0.016 & 0.009 & 0.883 & -0.016 & 0.009 \\
\hline External financial scrutiny (audit) & 0.892 & 0.038 & 0.019 & 0.860 & 0.037 & 0.021 & 0.890 & 0.038 & 0.020 \\
\hline Female top manager & 0.775 & 0.037 & 0.026 & 0.721 & 0.034 & 0.027 & 0.790 & 0.037 & 0.026 \\
\hline Culture of supply chain innovation & 0.772 & 0.023 & 0.016 & 0.721 & 0.021 & 0.017 & 0.780 & 0.023 & 0.016 \\
\hline Courts (as an obstacle) & 0.673 & -0.010 & 0.009 & 0.585 & -0.008 & 0.009 & 0.675 & -0.010 & 0.009 \\
\hline Innovation-specific training & 0.666 & 0.017 & 0.016 & 0.583 & 0.015 & 0.016 & 0.655 & 0.017 & 0.016 \\
\hline Investments & 0.534 & 0.013 & 0.015 & 0.453 & 0.011 & 0.014 & 0.535 & 0.013 & 0.015 \\
\hline Labour regulation (as an obstacle) & 0.391 & 0.004 & 0.006 & 0.328 & 0.003 & 0.006 & 0.390 & 0.004 & 0.006 \\
\hline Culture of product innovation & 0.341 & -0.006 & 0.011 & 0.276 & -0.005 & 0.010 & 0.318 & -0.006 & 0.011 \\
\hline Age of firm & 0.297 & 0.000 & 0.000 & 0.226 & 0.000 & 0.000 & 0.293 & 0.000 & 0.000 \\
\hline Revenue growth & 0.285 & 0.000 & 0.000 & 0.252 & 0.000 & 0.000 & 0.315 & 0.000 & 0.000 \\
\hline Manager tenure & 0.270 & 0.000 & 0.001 & 0.232 & 0.000 & 0.000 & 0.286 & 0.000 & 0.001 \\
\hline Shareholder ownership & 0.264 & 0.005 & 0.011 & 0.210 & 0.004 & 0.010 & 0.250 & 0.005 & 0.011 \\
\hline Electricity (as an obstacle) & 0.263 & 0.002 & 0.004 & 0.212 & 0.001 & 0.003 & 0.265 & 0.002 & 0.004 \\
\hline Business licensing (as an obstacle) & 0.234 & -0.002 & 0.005 & 0.195 & -0.001 & 0.004 & 0.241 & -0.002 & 0.005 \\
\hline Access to land (as an obstacle) & 0.188 & -0.001 & 0.003 & 0.169 & -0.001 & 0.003 & 0.187 & -0.001 & 0.003 \\
\hline Total annual costs & 0.185 & 0.000 & 0.000 & 0.164 & 0.000 & 0.000 & 0.182 & 0.000 & 0.000 \\
\hline Line of credit & 0.182 & 0.002 & 0.006 & 0.150 & 0.001 & 0.006 & 0.185 & 0.002 & 0.006 \\
\hline Access to finance (as an obstacle) & 0.179 & -0.001 & 0.003 & 0.152 & -0.001 & 0.003 & 0.187 & -0.001 & 0.003 \\
\hline Export orientation & 0.179 & 0.002 & 0.007 & 0.162 & 0.002 & 0.007 & 0.192 & 0.002 & 0.007 \\
\hline Crime and theft (as an obstacle) & 0.178 & 0.001 & 0.004 & 0.148 & 0.001 & 0.003 & 0.190 & 0.001 & 0.004 \\
\hline Total revenue & 0.162 & 0.000 & 0.000 & 0.132 & 0.000 & 0.000 & 0.149 & 0.000 & 0.000 \\
\hline Use of foreign-owned licenced technology & 0.160 & -0.001 & 0.007 & 0.120 & -0.001 & 0.006 & 0.145 & -0.001 & 0.007 \\
\hline Size of educated workforce & 0.158 & 0.000 & 0.000 & 0.122 & 0.000 & 0.000 & 0.146 & 0.000 & 0.000 \\
\hline Innovation-specific opportunity & 0.156 & 0.001 & 0.006 & 0.143 & 0.001 & 0.006 & 0.150 & 0.001 & 0.006 \\
\hline Banking facility & 0.155 & 0.001 & 0.014 & 0.122 & 0.001 & 0.013 & 0.138 & 0.001 & 0.013 \\
\hline Quality of labour force (as an obstacle) & 0.155 & 0.000 & 0.003 & 0.131 & 0.000 & 0.002 & 0.161 & 0.000 & 0.003 \\
\hline Formal staff training & 0.153 & -0.001 & 0.006 & 0.134 & -0.001 & 0.005 & 0.169 & -0.001 & 0.006 \\
\hline Expenditure of formal R\&D & 0.150 & 0.001 & 0.006 & 0.126 & 0.001 & 0.005 & 0.136 & 0.001 & 0.005 \\
\hline Political instability (as an obstacle) & 0.150 & 0.000 & 0.002 & 0.117 & 0.000 & 0.002 & 0.142 & 0.000 & 0.002 \\
\hline Size of skilled workers & 0.149 & 0.000 & 0.000 & 0.128 & 0.000 & 0.000 & 0.155 & 0.000 & 0.000 \\
\hline Firm growth & 0.148 & 0.000 & 0.000 & 0.115 & 0.000 & 0.000 & 0.135 & 0.000 & 0.000 \\
\hline Female ownership & 0.140 & 0.000 & 0.006 & 0.122 & 0.000 & 0.005 & 0.142 & 0.000 & 0.006 \\
\hline Part of a larger firm & 0.137 & 0.000 & 0.005 & 0.117 & 0.000 & 0.004 & 0.135 & 0.000 & 0.005 \\
\hline Email usage to communicate & 0.127 & 0.000 & 0.007 & 0.131 & 0.000 & 0.007 & 0.137 & 0.000 & 0.007 \\
\hline
\end{tabular}

Notes: The BMA results reported are based on 'hyper-g' parameter prior. PIPs above 0.86 are highlighted in bold as they imply significant effects on the propensity to learn. 
Table 2 Core determinants of the propensity to learn innovative management practices Panel A: Selection equation: the decision to learn management practices

$\log ($ Size)

0.105

$\log ($ Cost $)$

$[0.012] * * *$

0.087

Knowledge capital

$[0.030]^{* * *}$

0.753

$[0.083]^{* * *}$

0.007

Tenure

$[0.004]^{* *}$

2,903

Observations

$169.51 * * *$

Wald chi-squared

169.51**

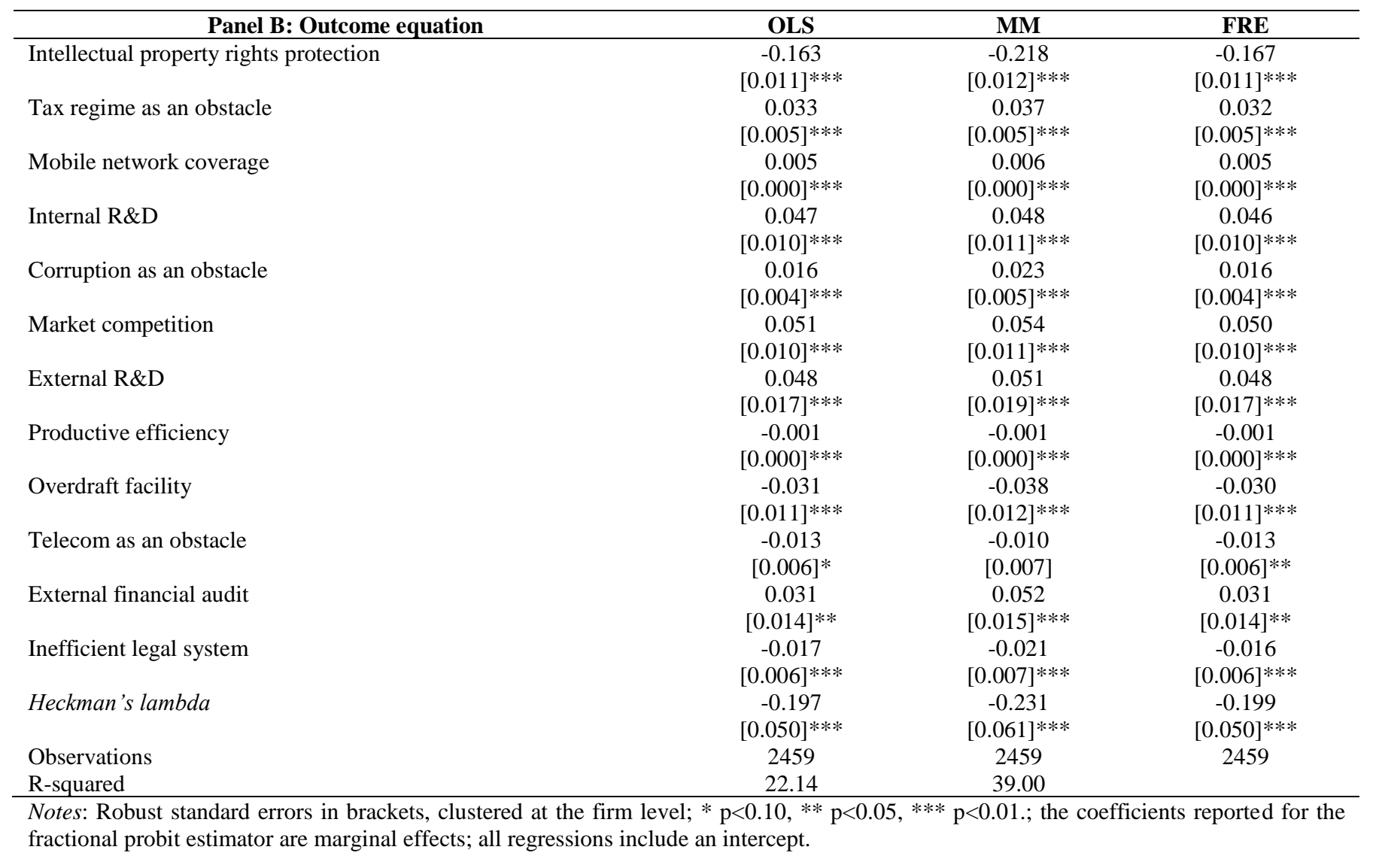


Table 3 Impact of the propensity to learn new management practices on actual and potential innovation

\section{Panel A: Selection equation}

\begin{tabular}{|c|c|c|c|c|c|c|c|c|}
\hline & \multicolumn{2}{|c|}{ Product innovation } & \multicolumn{2}{|c|}{ Process innovation } & \multicolumn{2}{|c|}{ Org. innovation } & \multicolumn{2}{|c|}{ Innovation capacity } \\
\hline \multirow[t]{2}{*}{ Knowledge capital } & \multirow{2}{*}{\multicolumn{2}{|c|}{$\begin{array}{c}0.353 \\
{[0.035]^{* * *}}\end{array}$}} & \multirow{2}{*}{\multicolumn{2}{|c|}{$\begin{array}{c}0.562 \\
{[0.036]^{* * *}}\end{array}$}} & \multirow{2}{*}{\multicolumn{2}{|c|}{$\begin{array}{c}0.585 \\
{[0.044]^{* * *}}\end{array}$}} & \multirow{2}{*}{\multicolumn{2}{|c|}{$\begin{array}{c}0.258 \\
{[0.019] * * *}\end{array}$}} \\
\hline & & & & & & & & \\
\hline \multirow[t]{2}{*}{ Innovation-specific opportunity } & \multicolumn{2}{|c|}{0.221} & \multicolumn{2}{|c|}{0.244} & \multicolumn{2}{|c|}{0.249} & \multicolumn{2}{|c|}{0.105} \\
\hline & \multicolumn{2}{|c|}{$[0.036]^{* * * *}$} & \multicolumn{2}{|c|}{$[0.036] * * *$} & \multicolumn{2}{|c|}{$[0.044]^{* * *}$} & \multicolumn{2}{|c|}{$[0.019] * * *$} \\
\hline \multirow[t]{2}{*}{ Log (Size) } & & & & & & & & \\
\hline & {$[0.01$} & ]*** & {$[0.01$} & ]*** & {$[0.0$} & ]*** & {$[0.0$} & ]$^{* * *}$ \\
\hline Services $^{\mathrm{a}}$ & -0 . & & & & & & & \\
\hline & {$[0.05$} & ]*** & {$[0.05$} & ]*** & {$[0.0$} & 8]** & {$[0.0$} & ]*** \\
\hline Trade & -0 . & & & & & & & \\
\hline & {$[0.0$} & $9]^{* *}$ & {$[0.06$} & ]*** & & & {$[0.0$} & ]*** \\
\hline Mature & & & & & & & & \\
\hline & {$[0.07$} & ]*** & & & & 9]* & & \\
\hline Old & 0.2 & & & & & & & \\
\hline & {$[0.07$} & ]*** & & & {$[0.0$} & $8] * *$ & & \\
\hline Observations & 55 & & & & & & & \\
\hline Wald chi-squared & 357. & $2 * * *$ & 592. & $3 * * *$ & 301. & $0 * * *$ & 1290 & $7 * * *$ \\
\hline Panel B: Outcome equation & Product i & novation & Process i & novation & Org. in & ovation & Innovati & capacity \\
\hline & [1a] & [1b] & [2a] & {$[2 \mathrm{~b}]$} & [3a] & [3b] & [4a] & {$[4 \mathrm{~b}]$} \\
\hline Management practices & 0.089 & 0.086 & 0.126 & 0.118 & 0.112 & 0.098 & 0.072 & 0.072 \\
\hline & {$[0.028]^{* * *}$} & {$[0.028]^{* * *}$} & {$[0.028]^{* * *}$} & {$[0.028]^{* * *}$} & {$[0.029]^{* * *}$} & {$[0.029]^{* * *}$} & {$[0.022]^{* * *}$} & {$[0.022]^{* * *}$} \\
\hline Expenditure on formal R\&D & 0.118 & 0.101 & 0.042 & -0.005 & 0.151 & 0.084 & 0.014 & -0.012 \\
\hline & {$[0.017] * * *$} & {$[0.018]^{* * *}$} & {$[0.018]^{* *}$} & {$[0.018]$} & {$[0.017] * * *$} & {$[0.018]^{* * *}$} & {$[0.014]$} & [0.014] \\
\hline Internal R\&D & 0.114 & 0.110 & 0.090 & 0.084 & 0.024 & 0.009 & 0.095 & 0.089 \\
\hline & {$[0.017]^{* * *}$} & {$[0.017]^{* * *}$} & {$[0.017]^{* * *}$} & {$[0.017]^{* * *}$} & {$[0.018]$} & {$[0.018]$} & {$[0.014]^{* * *}$} & {$[0.014]^{* * *}$} \\
\hline External R\&D & 0.077 & 0.075 & -0.023 & -0.022 & 0.091 & 0.087 & 0.007 & 0.010 \\
\hline & {$[0.028]^{* * *}$} & {$[0.028]^{* * *}$} & {$[0.027]$} & {$[0.027]$} & {$[0.028] * * *$} & {$[0.027]^{* * *}$} & {$[0.023]$} & {$[0.023]$} \\
\hline Mobile network coverage & 0.005 & 0.005 & 0.006 & 0.006 & -0.001 & -0.001 & 0.002 & 0.002 \\
\hline & {$[0.001]^{* * *}$} & {$[0.001]^{* * *}$} & {$[0.001]^{* * *}$} & {$[0.001]^{* * *}$} & {$[0.001]^{*}$} & [0.001] & {$[0.000]^{* * *}$} & {$[0.000]^{* * *}$} \\
\hline $\log ($ size $)$ & 0.013 & 0.005 & 0.015 & -0.008 & 0.031 & 0.003 & 0.051 & 0.010 \\
\hline & {$[0.007]^{*}$} & {$[0.008]$} & {$[0.008]^{* *}$} & {$[0.008]$} & {$[0.008] * * *$} & {$[0.008]$} & {$[0.006]^{* * *}$} & [0.009] \\
\hline Investments in fixed assets & 0.006 & 0.003 & 0.093 & 0.087 & 0.056 & 0.051 & 0.097 & 0.090 \\
\hline & {$[0.017]$} & [0.017] & {$[0.017] * * *$} & {$[0.017]^{* * *}$} & {$[0.017]^{* * *}$} & {$[0.017]^{* * *}$} & {$[0.014]^{* * *}$} & {$[0.013]^{* * *}$} \\
\hline Log (age) & -0.011 & -0.008 & -0.038 & -0.030 & -0.053 & -0.024 & -0.029 & -0.025 \\
\hline & {$[0.011]$} & [0.011] & {$[0.011]^{* * *}$} & {$[0.011]^{* * *}$} & {$[0.012]^{* * *}$} & {$[0.012]^{* *}$} & {$[0.009]^{* * *}$} & {$[0.009]^{* * *}$} \\
\hline Access to finance (as an obstacle) & -0.012 & -0.010 & 0.008 & 0.013 & -0.001 & 0.005 & 0.010 & 0.012 \\
\hline & [0.007] & [0.007] & {$[0.007]$} & {$[0.007]^{*}$} & {$[0.008]$} & {$[0.008]$} & {$[0.006]^{*}$} & {$[0.006]^{* *}$} \\
\hline Export orientation & 0.010 & 0.007 & 0.050 & 0.054 & -0.040 & -0.036 & 0.045 & 0.045 \\
\hline & {$[0.022]$} & [0.022] & {$[0.023]^{* *}$} & {$[0.022]^{* *}$} & {$[0.023]^{*}$} & {$[0.023]$} & {$[0.019]^{* *}$} & {$[0.019]^{* *}$} \\
\hline Telecom (as an obstacle) & -0.034 & -0.032 & -0.020 & -0.016 & -0.032 & -0.025 & -0.023 & -0.021 \\
\hline & {$[0.010]^{* * *}$} & {$[0.010]^{* * *}$} & {$[0.010]^{* *}$} & {$[0.010]$} & {$[0.011]^{* * * *}$} & {$[0.011]^{* *}$} & {$[0.008]^{* * *}$} & {$[0.008]^{* * *}$} \\
\hline Corruption (as an obstacle) & -0.012 & -0.016 & 0.024 & 0.019 & -0.015 & -0.021 & 0.009 & 0.006 \\
\hline & {$[0.006]^{*}$} & {$[0.006]^{* *}$} & {$[0.006]^{* * *}$} & {$[0.006]^{* * *}$} & {$[0.007]^{* *}$} & {$[0.007]^{* * *}$} & {$[0.005]^{*}$} & [0.005] \\
\hline Industry (group 1) ${ }^{\mathrm{b}}$ & 0.012 & -0.022 & 0.083 & 0.011 & -0.104 & -0.057 & 0.076 & 0.002 \\
\hline & {$[0.024]$} & {$[0.026]$} & {$[0.024] * * *$} & {$[0.026]$} & {$[0.025]^{* * *}$} & {$[0.026]^{* *}$} & {$[0.017]^{* * *}$} & {$[0.021]$} \\
\hline Industry (group 2) & 0.080 & 0.042 & 0.112 & 0.032 & -0.020 & 0.011 & 0.120 & 0.042 \\
\hline & {$[0.024]^{* * *}$} & {$[0.027]$} & {$[0.024] * * *$} & {$[0.026]$} & {$[0.025]$} & {$[0.025]$} & {$[0.017]^{* * *}$} & {$[0.022]^{*}$} \\
\hline Industry (group 3) & 0.108 & 0.072 & 0.144 & 0.057 & 0.011 & 0.029 & 0.154 & 0.071 \\
\hline & {$[0.024] * * *$} & {$[0.027]^{* * *}$} & {$[0.024] * * *$} & {$[0.026]^{* *}$} & {$[0.025]$} & {$[0.025]$} & {$[0.018]^{* * *}$} & {$[0.022] * * *$} \\
\hline Heckman's lambda & & -0.171 & & -0.338 & & -0.424 & & -0.348 \\
\hline & & {$[0.061] * * *$} & & {$[0.042]^{* * *}$} & & {$[0.037] * * *$} & & {$[0.060]^{* * *}$} \\
\hline Observations & 3444 & 3408 & 3442 & 3406 & 3423 & 3388 & 3301 & 3273 \\
\hline
\end{tabular}

Notes: Estimates based on the probit estimator except for the 'innovation capacity' model, which is based on FRE. Robust standard errors in brackets, clustred at the firm-level; * $\mathrm{p}<0.10, * * \mathrm{p}<0.05, * * * \mathrm{p}<0.01$; all regressions include an intercept. The dependent variables are coded 1 if the enterprise has introduced that particular type of actual innovation, and 0 otherwise. The 'innovation capacity'/ 'potential innovation' variable is an index between 0 and 1, capturing how many of the following a particular firm has: a) an internationally-recognised quality certification, b) newly-acquired machinery/software for innovation purposes; and 3) newly-acquired or licensed any patented/non-patented inventions or other types of knowledge for innovation purposes. ${ }^{a}$ For the selection equation, manufacturing and young firms are the reference categories. Young $=$ less than 5 years in operation; Mature $=5-15$ years; Old $=$ more than 15 years. ${ }^{b}$ For the industry classifications, group $1=$ agri-based industries; $2=$ mineral-based industries; and group 3= capital-intensive industries (for more details, see Nikaido et al., 2015). 
Table 4 Impact of the propensity to learn management practices on firm performance

\begin{tabular}{|c|c|c|c|c|c|c|c|c|c|c|c|c|}
\hline & (1) & (2) & (3) & (4) & (5) & (6) & (7) & (8) & (9) & (10) & (11) & (12) \\
\hline Management practices & $\begin{array}{c}3.593 \\
{[0.818]^{* * *}}\end{array}$ & $\begin{array}{c}3.548 \\
{[0.818]^{* * *}}\end{array}$ & $\begin{array}{c}3.647 \\
{[0.905]^{* * *}}\end{array}$ & $\begin{array}{c}3.493 \\
{[0.921]^{* * *}}\end{array}$ & $\begin{array}{c}3.368 \\
{[0.923]^{* * *}}\end{array}$ & $\begin{array}{c}3.402 \\
{[0.920]^{* * *}}\end{array}$ & $\begin{array}{c}3.479 \\
{[0.929]^{* * *}}\end{array}$ & $\begin{array}{c}3.402 \\
{[0.954]^{* * *}}\end{array}$ & $\begin{array}{c}3.350 \\
{[0.958]^{* * *}}\end{array}$ & $\begin{array}{c}3.228 \\
{[1.053]^{* * *}}\end{array}$ & $\begin{array}{c}3.280 \\
{[1.072]^{* * *}}\end{array}$ & $\begin{array}{c}3.216 \\
{[1.079]^{* * *}}\end{array}$ \\
\hline Investments & & $\begin{array}{c}3.587 \\
{[0.521]^{* * *}}\end{array}$ & $\begin{array}{c}3.897 \\
{[0.595]^{* * *}}\end{array}$ & $\begin{array}{c}3.618 \\
{[0.611]^{* * *}}\end{array}$ & $\begin{array}{c}3.439 \\
{[0.607]^{* * *}}\end{array}$ & $\begin{array}{c}3.474 \\
{[0.604]^{* * *}}\end{array}$ & $\begin{array}{c}3.428 \\
{[0.607]^{* * *}}\end{array}$ & $\begin{array}{c}3.442 \\
{[0.611]^{* * *}}\end{array}$ & $\begin{array}{c}3.513 \\
{[0.616]^{* * *}}\end{array}$ & $\begin{array}{c}3.910 \\
{[0.653]^{* * *}}\end{array}$ & $\begin{array}{c}3.858 \\
{[0.656]^{* * *}}\end{array}$ & $\begin{array}{c}3.755 \\
{[0.664]^{* * *}}\end{array}$ \\
\hline Productive efficiency & & & $\begin{array}{c}0.043 \\
{[0.015]^{* * *}}\end{array}$ & $\begin{array}{c}0.053 \\
{[0.015]^{* * *}}\end{array}$ & $\begin{array}{c}0.050 \\
{[0.015]^{* * *}}\end{array}$ & $\begin{array}{c}0.052 \\
{[0.015]^{* * *}}\end{array}$ & $\begin{array}{c}0.049 \\
{[0.016]^{* * *}}\end{array}$ & $\begin{array}{c}0.056 \\
{[0.016]^{* * *}}\end{array}$ & $\begin{array}{c}0.057 \\
{[0.016]^{* * *}}\end{array}$ & $\begin{array}{c}0.056 \\
{[0.019]^{* * *}}\end{array}$ & $\begin{array}{c}0.056 \\
{[0.019]^{* * *}}\end{array}$ & $\begin{array}{c}0.055 \\
{[0.019]^{* * * *}}\end{array}$ \\
\hline Line of credit & & & & $\begin{array}{c}2.496 \\
{[0.551]^{* * *}}\end{array}$ & $\begin{array}{c}2.478 \\
{[0.552]^{* * *}}\end{array}$ & $\begin{array}{c}2.388 \\
{[0.555]^{* * *}}\end{array}$ & $\begin{array}{c}2.221 \\
{[0.560]^{* * *}}\end{array}$ & $\begin{array}{c}2.229 \\
{[0.560]^{* * *}}\end{array}$ & $\begin{array}{c}2.227 \\
{[0.562]^{* * *}}\end{array}$ & $\begin{array}{c}2.076 \\
{[0.589]^{* * *}}\end{array}$ & $\begin{array}{c}2.045 \\
{[0.592] * * *}\end{array}$ & $\begin{array}{c}1.968 \\
{[0.588]^{* * *}}\end{array}$ \\
\hline Foreign-licenced tech. & & & & & $\begin{array}{c}2.156 \\
{[0.728]^{* * *}}\end{array}$ & $\begin{array}{c}2.074 \\
{[0.725]^{* * *}}\end{array}$ & $\begin{array}{c}2.375 \\
{[0.737]^{* * *}}\end{array}$ & $\begin{array}{c}2.450 \\
{[0.733]^{* * *}}\end{array}$ & $\begin{array}{c}2.419 \\
{[0.736]^{* * *}}\end{array}$ & $\begin{array}{c}2.678 \\
{[0.794]^{* * *}}\end{array}$ & $\begin{array}{c}2.667 \\
{[0.795]^{* * *}}\end{array}$ & $\begin{array}{c}2.800 \\
{[0.788]^{* * *}}\end{array}$ \\
\hline Telecom (as an obstacle) & & & & & & $\begin{array}{c}-0.591 \\
{[0.335]^{*}}\end{array}$ & $\begin{array}{c}-0.644 \\
{[0.337]^{*}}\end{array}$ & $\begin{array}{c}-0.560 \\
{[0.344]}\end{array}$ & $\begin{array}{c}-0.525 \\
{[0.356]}\end{array}$ & $\begin{array}{c}-0.922 \\
{[0.423]^{* *}}\end{array}$ & $\begin{array}{c}-0.878 \\
{[0.450]^{*}}\end{array}$ & $\begin{array}{c}-0.948 \\
{[0.456]^{* *}}\end{array}$ \\
\hline Inefficient legal system & & & & & & & $\begin{array}{c}-0.146 \\
{[0.269]}\end{array}$ & $\begin{array}{c}-0.256 \\
{[0.272]}\end{array}$ & $\begin{array}{c}-0.255 \\
{[0.274]}\end{array}$ & $\begin{array}{c}-0.170 \\
{[0.296]}\end{array}$ & $\begin{array}{c}-0.181 \\
{[0.299]}\end{array}$ & $\begin{array}{c}-0.087 \\
{[0.298]}\end{array}$ \\
\hline Overdraft facility & & & & & & & & $\begin{array}{c}-1.021 \\
{[0.549]^{*}}\end{array}$ & $\begin{array}{c}-1.051 \\
{[0.550]^{*}}\end{array}$ & $\begin{array}{c}-0.959 \\
{[0.605]}\end{array}$ & $\begin{array}{c}-0.954 \\
{[0.607]}\end{array}$ & $\begin{array}{c}-1.094 \\
{[0.612]^{*}}\end{array}$ \\
\hline Log (age) & & & & & & & & & $\begin{array}{c}0.054 \\
{[0.316]}\end{array}$ & $\begin{array}{l}-0.305 \\
{[0.376]}\end{array}$ & $\begin{array}{c}-0.319 \\
{[0.383]}\end{array}$ & $\begin{array}{c}-0.301 \\
{[0.378]}\end{array}$ \\
\hline Revenue growth & & & & & & & & & & $\begin{array}{c}0.002 \\
{[0.000]^{* * *}}\end{array}$ & $\begin{array}{c}0.002 \\
{[0.000]^{* * *}}\end{array}$ & $\begin{array}{c}0.002 \\
{[0.000]^{* * *}}\end{array}$ \\
\hline Corruption (as an obstacle) & & & & & & & & & & & $\begin{array}{c}-0.106 \\
{[0.238]}\end{array}$ & $\begin{array}{c}-0.059 \\
{[0.237]}\end{array}$ \\
\hline External auditor & & & & & & & & & & & & $\begin{array}{c}1.340 \\
{[0.757]^{*}}\end{array}$ \\
\hline Constant & $\begin{array}{c}3.608 \\
{[0.526]^{* * *}}\end{array}$ & $\begin{array}{c}2.489 \\
{[0.514]^{* * *}}\end{array}$ & $\begin{array}{l}-1.866 \\
{[1.336]}\end{array}$ & $\begin{array}{c}-3.371 \\
{[1.368]^{* *}}\end{array}$ & $\begin{array}{c}-3.229 \\
{[1.367]^{* *}}\end{array}$ & $\begin{array}{c}-3.107 \\
{[1.366]^{* *}}\end{array}$ & $\begin{array}{c}-2.622 \\
{[1.366]^{*}}\end{array}$ & $\begin{array}{c}-2.493 \\
{[1.420]^{*}}\end{array}$ & $\begin{array}{l}-2.672 \\
{[1.736]}\end{array}$ & $\begin{array}{l}-1.569 \\
{[2.077]}\end{array}$ & $\begin{array}{l}-1.289 \\
{[2.240]}\end{array}$ & $\begin{array}{l}-2.468 \\
{[2.291]}\end{array}$ \\
\hline$N$ & 3547 & 3513 & 2786 & 2719 & 2702 & 2699 & 2632 & 2603 & 2594 & 2347 & 2341 & 2320 \\
\hline
\end{tabular}

Notes: Estimates based on the MM estimator. Robust standard errors in brackets; $* \mathrm{p}<0.10, * * \mathrm{p}<0.05, * * * \mathrm{p}<0.01 ;$ the dependent variable is employment growth over the past 3 years. 